\title{
Bird and bat predation services in tropical forests and agroforestry landscapes
}

Bea Maas ${ }^{1,2^{*}}$, Daniel S. Karp ${ }^{3,4}$, Sara Bumrungsri ${ }^{5}$, Kevin Darras ${ }^{1}$, David Gonthier $^{3,6}$, Joe C.-C. Huang ${ }^{7,8}$, Catherine A. Lindel1 ${ }^{9}$, Josiah J. Maine ${ }^{10}$, Laia Mestre $^{11,12,13}$, Nicole L. Michel ${ }^{14}$, Emily B. Morrison ${ }^{9}$, Ivette Perfecto ${ }^{6}$, Stacy M. Philpott $^{15}$, Çagan H. ekercio $\mathrm{lu}^{16,17}$, Roberta M. Silva ${ }^{18}$, Peter J. Taylor ${ }^{19,20}$, Teja Tscharntke ${ }^{1}$, Sunshine A. Van Bael ${ }^{21,22}$, Christopher J. Whelan ${ }^{23}$ and Kimberly Williams-Guillén ${ }^{24,6}$

${ }^{1}$ Agroecology, Georg-August University, Grisebachstraße 6, 37077, Goettingen, Germany ${ }^{2}$ Department of Botany and Biodiversity Research, Division of Tropical Ecology and Animal Biodiversity, University of Vienna, Rennweg 14, 1030, Vienna, Austria

${ }^{3}$ The Nature Conservancy, Berkeley, CA 94105, USA

${ }^{4}$ Department of Environmental Science, Policy, and Management, University of California, Mulford Hall, 130 Hilgard Way, Berkeley, CA 94720, USA

${ }^{5}$ Department of Biology, Faculty of Science, Prince of Songkla University, Hat Yai, Songkhla, 90112, Thailand

${ }^{6}$ School of Natural Resources and Environment, University of Michigan, 440 Church Street Ann Arbor, MI 48109, USA

${ }^{7}$ Department of Biological Sciences, Box 43131, Texas Tech University, Lubbock, TX 79409, USA

${ }^{8}$ Southeast Asian Bat Conservation and Research Unit, Lubbock, TX 79409, USA

${ }^{9}$ Integrative Biology Department, Center for Global Change and Earth Observations, Michigan State University, 288 Farm Lane RM 203, East Lansing, MI 48824 USA

${ }^{10}$ Cooperative Wildlife Research Laboratory, Department of Zoology, and Center for Ecology, Southern Illinois University, 1125 Lincoln Dr., Carbondale, IL 62901, USA

${ }^{11}$ CREAF, Cerdanyola del Vallès, 08193, Barcelona, Spain

${ }^{12}$ Departament de Biologia Animal, de Biologia Vegetal i d'Ecologia, Universitat Autònoma de Barcelona, Cerdanyola del Vallès, 08193, Barcelona, Spain

${ }^{13}$ Department of Ecology, Swedish University of Agricultural Sciences, Box 7044, 750 07, Uppsala, Sweden

${ }^{14}$ School of Environment and Sustainability, University of Saskatchewan, 117 Science Place, Saskatoon, SK, S7N 5C8, Canada

${ }^{15}$ Environmental Studies Department, University of California, Santa Cruz, 1156 High Street, Santa Cruz, CA, 95062, USA

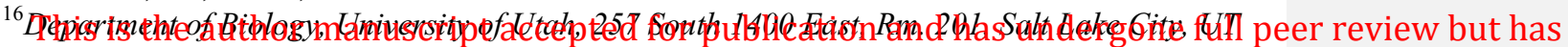

84112 , USA through the copyediting, typesetting, pagination and proofreading process, which may lead to differences between this version and the Version of Record. Please cite this article as doi:

$10.1111 /$ brv.12211 


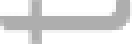 \\ ${ }^{17}$ College of Sciences, Koç University, Rumelifeneri, Sariyer 34450, Istanbul, Turkey \\ ${ }^{18}$ Programa de Pós-Graduação em Ecologia e Conservação da Biodiversidade, Universidade \\ Estadual de Santa Cruz, Rodovia Ilhéus-Itabuna, km 16, 45662-900, Bahia, Brazil \\ ${ }^{19}$ School of Life Sciences, University of KwaZulu-Natal, Private Bag X54001, Durban, 4000, \\ South Africa \\ ${ }^{20}$ SARChI Chair on Biodiversity Value \& Change and Centre for Invasion Biology, School of \\ Mathematical \& Natural Sciences, University of Venda, P. Bag X5050, Thohoyandou, 0950, \\ South Africa \\ ${ }^{21}$ Department of Ecology and Evolutionary Biology, Tulane University, 6823 St. Charles Avenue, \\ New Orleans, LA 70118, USA \\ ${ }^{22}$ Smithsonian Tropical Research Institute, Apartado Postal 0843-03092, Balboa, Ancon, \\ Republic of Panama \\ ${ }^{23}$ Illinois Natural History Survey, c/o Biological Sciences, University of Illinois at Chicago, 845 \\ West Taylor Street, Chicago, IL 60607, USA \\ ${ }^{24}$ Paso Pacífico, PO Box 1244, Ventura, CA 94302, USA
}

Running head: Ecosystem services provided by tropical birds and bats

*Author for correspondence (E-mail: beamaas@gmx.at; Tel.: +43(0)6504200494).

\section{ABSTRACT}

Understanding distribution patterns and multitrophic interactions is critical for managing bat- and bird-mediated ecosystem services such as the suppression of pest and non-pest arthropods.

Despite the ecological and economic importance of bats and birds in tropical forests, agroforestry systems, and agricultural systems mixed with natural forest, a systematic review of their impact is still missing. A growing number of bird and bat exclosure experiments has improved our knowledge allowing new conclusions regarding their roles in food webs and associated ecosystem services. Here, we review the distribution patterns of insectivorous birds and bats, their local and landscape drivers, and their effects on trophic cascades in tropical ecosystems. We report that for birds but not bats community composition and relative importance of functional groups changes conspicuously from forests to habitats including both agricultural areas and 
forests, here termed 'forest-agri' habitats, with reduced representation of insectivores in the latter. In contrast to previous theory regarding trophic cascade strength, we find that birds and bats reduce the density and biomass of arthropods in the tropics with effect sizes similar to those in temperate and boreal communities. The relative importance of birds versus bats in regulating pest abundances varies with season, geography and management. Birds and bats may even suppress tropical arthropod outbreaks, although positive effects on plant growth are not always reported. As both bats and birds are major agents of pest suppression, a better understanding of the local and landscape factors driving the variability of their impact is needed.

Key words: agricultural landscapes, arthropod suppression, bird and bat ecology, cacao, coffee, ecosystem services, exclosure experiments, flying vertebrates, food webs, pest suppression.

\section{CONTENTS}

I. Introduction ..............

II. Methods

(1) Data sources and preparation

(2) Bat species richness and endemism per biogeographical region

(3) Mapping feeding-guild distributions of birds and bats

(4) Bat species richness and feeding guilds per habitat

(5) Effect sizes of bird/bat exclosure studies on different arthropod groups

III. Zoogeography of birds and bats - species richness and functional diversity 12

(1) Zoogeography of birds and bats - species richness 13

(2) Zoogeography of birds and bats - feeding guilds................................................... 14

(3) Birds and bats in different land-use systems ............................................................... 15

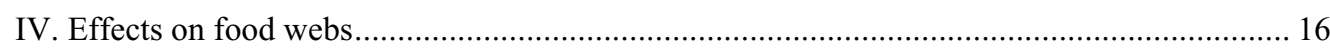

(1) Bird and bat effects on arthropods and plants in tropical communities 17 
(2) Factors influencing tropical trophic cascade strength
(a) Insectivore identity
(b) Insectivore foraging strategy
(c) Insectivore diversity and abundance
(d) Presence of migratory birds
(e) Intraguild predation
(f) Herbivore density
(g) Productivity
(h) Plant ontogeny and defences
(i) Natural versus agricultural systems

V. Bird and bat services in agricultural systems.

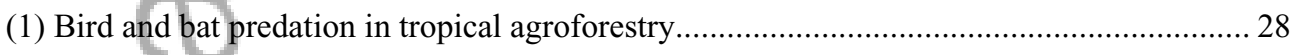

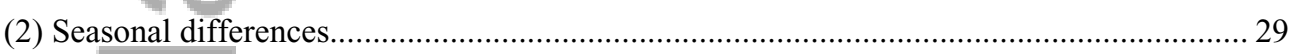

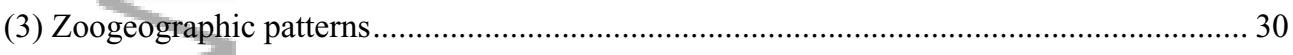

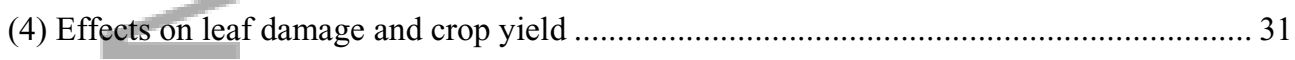

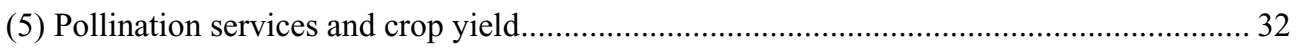

VI. Local and landscape-management effects ...................................................................... 32

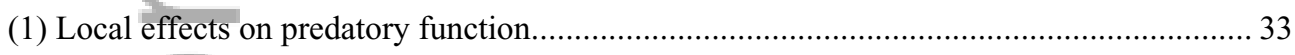

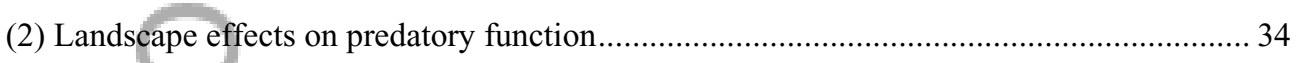

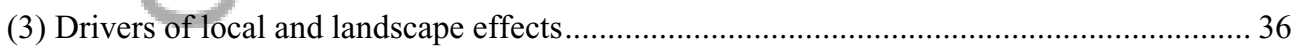

VII. Knowledge gaps and need for further studies ................................................................ 38

VIII. Management of bird and bat ecosystem services .......................................................... 42

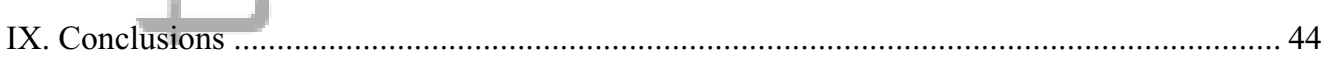

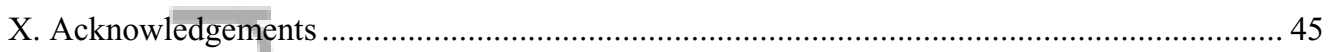

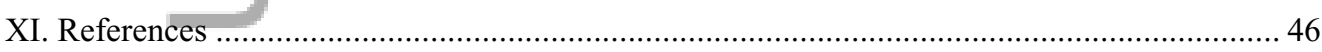

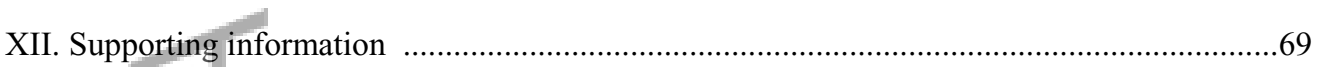

\section{INTRODUCTION}

Agricultural expansion and land-use intensification now typify landscapes globally (Melo et al., 2013; Laurance, Sayer \& Cassman, 2014), representing a serious threat to biodiversity and 


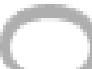

ecosystem processes (Flynn et al., 2009). Maintaining ecosystem services - the benefits that

$=$ in

nature provides to humanity - is more important than ever as demand for food, fuel, fibre and other biological products grows (Millenium Ecosystem Assessment, 2005), and Earth's climate changes (McShane et al., 2011; Urban, Zarnetske \& Skelly, 2013).

Birds and bats provide many important ecosystem services such as the suppression of insect pests, seed dispersal, and pollination (Whelan, Wenny \& Marquis, 2008; Kunz et al., 2011; ekercio lu, Wenny \& Whelan, 2016). It is hard to overstate the economic importance of the services rendered by these taxa (e.g. Cleveland et al., 2006; Boyles et al., 2011, 2013). In particular, the suppression of pest insects by birds and bats in tropical agroforestry systems facilitates substantial increases in crop yields (Karp et al., 2013; Maas, Clough \& Tscharntke, 2013) and may serve as a viable alternative to pesticides and other chemical compounds (e.g. Bianchi, Booij \& Tscharntke, 2006; Clough, Faust \& Tscharntke, 2009b). Biodiversity-friendly management of tropical farming landscapes thus provides a promising conservation strategy while enhancing human well-being through support of food security and ecosystem resilience (Fischer, Lindenmayer \& Manning, 2006; Tscharntke et al., 2012a).

However, the impact of insectivorous birds and bats on arthropod communities, plant productivity and yield as well as the underlying taxonomic and functional drivers, are highly variable and the existing knowledge is still unbalanced and limited. Insectivorous birds and bats consume a wide variety of arthropods: not only herbivorous pests (e.g. ekercio lu, 2006a; Whelan et al., 2008; Kunz et al., 2011; Morrison \& Lindell, 2012; Taylor et al., 2013a) but also predatory arthropods, such as ants and spiders (e.g. Mooney \& Linhart, 2006; Gunnarsson, 2007). Therefore, while birds and bats often improve crop yields directly by consuming herbivorous insects, they may at times depress crop yields through feeding as intraguild predators 


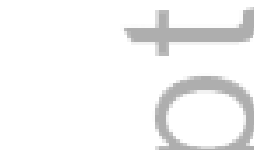

(consuming both intermediate predators and herbivores). Whether birds and bats will ultimately<smiles>[CH]C=C</smiles>

suppress herbivores and contribute to yield productivity likely depends on specific functional traits (Philpott et al., 2009) as well as on factors such as geographic distribution (Olson et al., 2001), seasonality (e.g. Erickson \& West, 2002; Williams-Guillén, Perfecto \& Vandermeer, 2008; Singer et al., 2012; Taylor, Monadjem \& Steyn, 2013b), landscape context (e.g. Fahrig et $a l ., 2011$ ), and local habitat structure or management regimes (e.g. Loeb \& O'Keefe, 2006; Rice \& Greenberg, 2000; Bhagwat et al., 2008; Maas et al., 2009).

Managing bird- and bat-mediated ecosystem services thus requires thorough understanding of multitrophic interactions, seasonal patterns (e.g. resource availability; precipitation; breeding cycles; presence of latitudinal effects and migrants) and the broader landscape context. Fortunately, community-wide manipulation experiments (e.g. experimental exclosures) can be readily used to identify the complex interactions between vertebrates and invertebrates that affect ecosystem services. In such studies, plants are enclosed in mesh nets that prevent access to foraging birds and bats while remaining accessible to arthropods. The relative impacts of bird- and bat-mediated predation on arthropod communities can then be isolated through deploying exclosures either during the day (to exclude only birds), at night (to exclude only bats and night-active birds), or throughout the daily cycle to assess joint impacts of birds and bats. Until recently, only the latter method was used in exclosure studies, with investigators attributing changes in arthropod density and plant damage exclusively to birds (Marquis \& Whelan, 1994; Greenberg et al., 2000b; Johnson, Kellermann \& Stercho, 2010) and not to bats (e.g. Kalka \& Kalko, 2006; Kunz et al., 2011; Williams-Guillén et al., 2008).

In recent years, however, several exclosure experiments have demonstrated that both birds and bats significantly constrain arthropod populations, yet major knowledge gaps persist. 


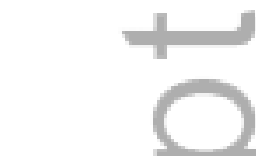

For example, few studies have addressed the influence of local and landscape management on pest control, as well as the ultimate effect of bird and bat predation on crop yields (Kellermann et al., 2008; Johnson et al., 2010; Karp et al., 2013; Maas et al., 2013), hampering the design of targeted service management. In addition, study sites have been biased, with the Paleotropics underrepresented (Maas et al., 2013) compared to the Neotropics (e.g. Van Bael \& Brawn, 2005; Kalka, Smith \& Kalko, 2008; Williams-Guillén et al., 2008; Morrison \& Lindell, 2012; Karp et al., 2013).

Here, we compare arthropod suppression services of insectivorous birds and bats in tropical forest, agroforestry systems, and agricultural systems mixed with natural forest (here referred to as forest-agri systems), focusing on a growing number of landscape-scale exclosure experiments. Through comprehensive review and discussion of previous results, we describe trophic interactions among birds, bats and arthropods, the importance of environmental factors and biogeographic patterns in relation to vertebrate ecosystem functions, and address existing research gaps. We conducted a comprehensive literature search as well as a focused solicitation from colleagues for studies focusing on the role of birds and/or bats in regulating arthropod communities. Our search yielded 32 publications in which exclusions of birds and bats were used to quantify the effects of flying vertebrate predation on different arthropod groups. These publications provide the basis for our discussions of birds and bats in tropical agroforestry systems (i.e. coffee, cacao, and mixed fruit orchard) and forests, combining both prominent and new publications on bird and bat ecosystem services.

In Section III, we provide an overview of zoogeographic patterns of bird and bat species and their functional diversity (feeding guilds, habitat affiliations). Section IV unravels general effects of birds and bats on arthropod food webs and plants via trophic cascades and discusses the 


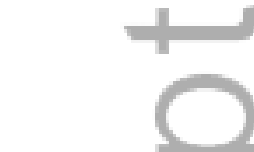

factors modulating these top-down effects. The importance of predation services in diversely managed agricultural landscapes and tropical communities, with particular focus on the economic importance of birds and bats, is discussed in Section V. Existing evidence for local and landscape-management effects on bird and bat predatory functions is described in Section VI. Finally, in Sections VII and VIII, we point out existing knowledge gaps and highlight the potential for bird- and bat-mediated arthropod suppression to contribute to food security and improved landscape management in the tropics, with important implications for future biodiversity conservation and research. Together, our conclusions contribute to both a practical and theoretical framework for the study and management of tropical landscapes affected by ongoing agricultural expansion and biodiversity loss.

\section{METHODS}

\section{(1) Data source and preparation}

Quantum Gis 2.6(QGis) was used for all Geographic Information System (GIS) operations. Bird data were taken from a database with standardized entries on the ecology of the bird species of the world. See , Dekiliscis Fithrlich (2004) and (20kezdiforlfurther details. For bats, the terrestrial mammals shapefile was downloaded from the International Union for Conservation of Nature and Natural Resources (IUCN) Red List website (in May 2014); records not pertaining to Chiroptera were deleted. Records with presence codes different from 1 and 2 (extant and probably extant, respectively), and with seasonal codes different from 1, 2 and 3 (resident, breeding season and non-breeding season, respectively), were deleted. The separate bat distribution polygons were merged into multipart polygons for each species, to yield our bat distribution layer. The landmass polygon layer was obtained from 
http://www.naturalearthdata.com. The biogeographic realms were drawn by hand in QGis based on the realms defined by Olson et al. (2001). The tabular IUCN Red List data on Chiroptera, incorporating full taxonomic data, were downloaded and imported into a Microsoft Access database.

\section{(2) Bird and bat species richness and endemism per biogeographic region}

Bird data were updated from exker(20014) and ekercio lu (2012), with new ornithological data published until 2014. For bats, spatial queries between the IUCN bat distribution data (IUCN, 2014) and the biogeographic realms layers (following Olson et al., 2001) were made to determine bat species richness and number of endemic species in each region: each realm's polygon was intersected with the bat distribution layer to find the total species richness, and the number of bat polygons contained exclusively within each realm was counted to derive the endemic species richness.

\section{(3) Mapping feeding-guild distributions of birds and bats}

Bird data were taken from a database with standardized entries on the ecology of the bird species of the world. See exker(20014) and (20kezdiforlfurther details. Bat data were based on diet data mainly from IUCN and the Animal Diversity Web (both retrieved in May 2014), except for 14 species whose diet was retrieved from other scientific publications.

Feeding-guild data for birds and bats were adapted to be comparable between the two groups. All bat diet data were entered into an Access database. For bat species-rich genera, when diet was unequivocal and consistent for multiple species, the remaining species were assigned the 


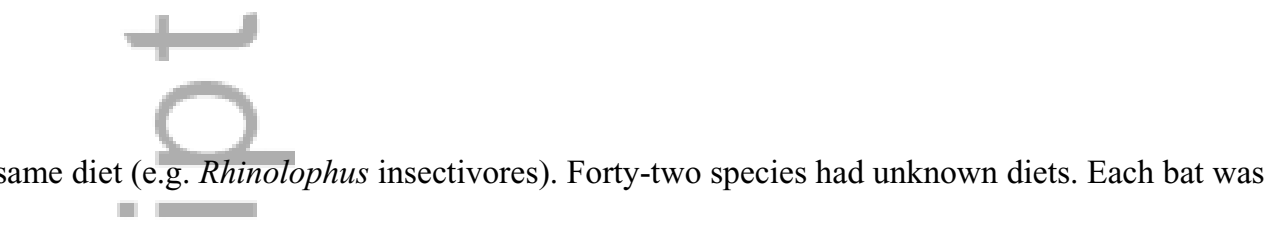
then assigned to one feeding guild (see below), depending on its main diet, which could comprise multiple items (e.g. insects and fruits). Bats were classified into the omnivorous guild whenever their diet comprised plant and animal matter.

Bird feeding guilds from ekercio lu et al. (2004) were adapted to be comparable with bats: the vertebrate-feeding guild was obtained by merging vertebrate-, scavenger, and fishfeeding guilds, the plant-feeding guild was obtained by merging the fruit- and plant-feeding guilds (see below). Note that omnivorous birds only belonged to that guild when no clear main diet could be found, which is different from bats. Therefore the omnivorous bird guild is slightly underestimated in birds - or the bat omnivorous guild overestimated - and both are not directly comparable.

Feeding guilds were defined as follows: $(a)$ invertebrate-feeding guild (only arthropods for bats). (b) Vertebrate-feeding guild (including avian scavengers, fish predators and bloodfeeding bats). (c) Omnivorous birds and bats [see ekercio lu et al. (2004) and ekercio lu (2012) for the omnivorous guild definition of birds; omnivorous bats were defined as feeding on both plant and animal matter]. (d) Seed-feeding guild (only birds). (e) Fruit-, leaf-, flower- and bark-feeding birds and bats. [This class was largely dominated by fruit-feeding species. Eighty per cent of the world's plant-feeding (nectar and seeds excluded) birds feed on fruit; the remaining $20 \%$ feed on plant parts other than seeds, fruit, or nectar. Ninety-two per cent of plantfeeding bats (nectar excluded) feed on fruit, the remaining $8 \%$ feed on leaves, flowers, and bark]. (f) Nectar- and pollen-feeding birds and bats.

To generate the world map for both birds and bats (see Fig. 1), we calculated percentage proportions of feeding guilds and total richness numbers for each realm. For birds, the latter were 


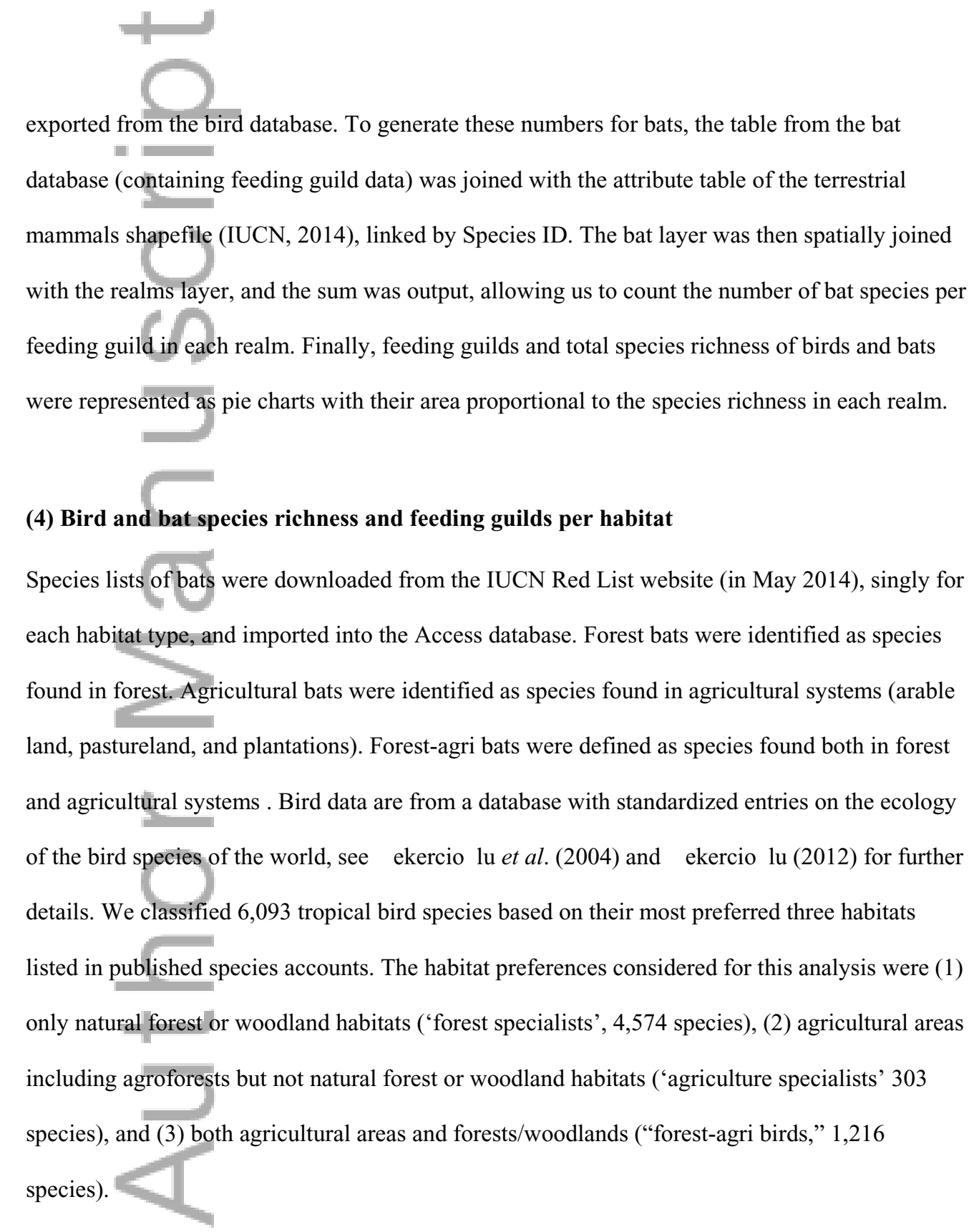




\section{2. \\ (2) \\ (5) Effect sizes of bird/bat exclosure studies on different arthropod groups \\ Iin}

We collected data from 32 exclosure studies on birds and bats from tropical agroforestry systems (i.e. cacao, coffee, mixed fruit orchard) and forests (seven tropical countries) to compare effects of predatory birds and bats on the abundance of herbivorous insects, ants, spiders and arthropods in general (see online supporting information, Table S1). We compare mean arthropod abundances in unmanipulated control treatments to experimental exclosures of birds, bats and birds+bats. Effect sizes were calculated as the logarithm of the ratio of insect abundance in the control versus the exclosure, then graphed in $\mathrm{R}$ (3.1) with the package ggplot2.

\section{ZOOGEOGRAPHY OF BIRDS AND BATS - SPECIES RICHNESS AND FUNCTIONAL DIVERSITY}

As flying vertebrates, bats and birds share several characteristics that allow them to provide important ecosystem services (Fujita \& Tuttle, 1991; Muscarella \& Fleming, 2007; ekercio lu, 2006a, b; Whelan et al., 2008; Kunz et al., 2011;

etkerca016i). Many bat and bird species, owing to their capacity for flight, are highly vagile and thus capable of moving across complex landscapes, allowing both opportunistic tracking of shifting food resources (Barber, Marquis \& Tori, 2008; Richter \& Cumming, 2008; McCracken et al., 2012) and the linkage of distinct geographic areas through seed dispersal and transport of nutrients and energy (Whelan et al., 2008; Kunz et al., 2011). Many studies of both birds and bats also demonstrate significant arthropod-suppression services in natural and human-modified habitats. Nevertheless, we know substantially less about the ecological functions and services of birds and bats in the tropics than we do in the temperate zone. There is particular urgency in understanding how human-driven changes in the richness, abundance and proportions of various species will affect ecosystem 


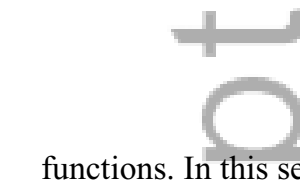

functions. In this section, we summarize patterns of bird and bat species richness and functional diversity in different zoogeographic regions and habitats.

\section{(1) Zoogeography of birds and bats - species richness}

More than a third $(3,564)$ of the world's approximately 10,300 bird species are found only in the Neotropics, and an additional 320 species migrate there for most of the year after breeding in the Nearctic region ( ekercio lu et al., 2004). The highest endemic species richness in the Neotropics is followed by the Afrotropics (1,671 species), Indomalaya including Wallacea (1,242 species), Australasia (Australia, Papua New Guinea, and surrounding islands: 1,019 species), and temperate and polar regions (Nearctic, Palearctic, New Zealand, Antarctica, and sub-Antarctic islands: 757 species) (Table 1). Only 1\% of the world's bird species (98 species) are truly cosmopolitan, found on all continents except Antarctica. Another 150 species are found on most of the continents in the eastern hemisphere.

According to the IUCN Red List data on Chiroptera (IUCN, 2014), more than $80 \%$ of the world's 1,232 bat species (Kunz et al., 2011) are found in the tropics (Australasia, Oceania, Afrotropics, Indomalaya, and Neotropics). Of these, 785 [spatial data from IUCN (2014) for 1,133 bat species] occur only in the tropics. The Neotropics harbour the most bat species (337), followed by Indomalaya (282), Australasia (270) and the Afrotropics (237, Table 1). No bat species is found in the Antarctic and no bat species is cosmopolitan (found in all biogeographic realms). Tropical realms have high percentages of endemic species (approximately 68-89\%), though Indomalaya falls notably short (approximately 44\%), as a consequence of being situated at the convergence of many realms. 


\section{In \\ Cons \\ (2) Zoogeography of birds and bats - feeding guilds}

Most avian feeding guilds (often used as a proxy for functional groups; $c f$. Philpott et al., 2008) reach their peak richness in the Neotropics (Kissling, ekercio lu \& Jetz, 2012; Fig. 1).

However, proportionate representation of avian feeding guilds varies across biogeographic realms. Insectivores and frugivores have the highest representation in the tropics, with frugivores and insectivores being proportionally lower in the Afrotropics and in Australasia, respectively. Seed-eaters are well-represented in drier parts of the world, especially in Australasia, the Afrotropics and temperate regions. Nectarivores, on the other hand, reach their highest proportions in the Neotropics (home of the hummingbird radiation), the Pacific Ocean islands, and Australia. Scavengers (vertebrate-feeding guild) reach their highest species richness in the savannas of eastern Africa. Finally, piscivores (fish-eaters), carnivores (birds of prey), and herbivores are better represented in the temperate zone than in the tropics.

All bat communities are dominated by the invertebrate-feeding guild, comprised almost exclusively by insectivores (Fig. 1). The Palearctic has the highest proportion of insectivores but not the highest number of insectivorous species. As with birds, the species richness of fruit and nectar-feeding bats peaks in the tropics. Indomalaya and the Afrotropics have higher proportions of nectar and fruit-feeding guilds than temperate realms, but distinctly below the proportions found in the Neotropics, Oceania, and Australasia. Overall, herbivorous bats, the great majority of which are frugivorous, outweigh nectar-feeding bats in species number. The Neotropics represents the most speciose realm (Table 1), and harbours by far the majority of omnivorous bat species (56) and the lowest proportion of invertebrate-feeding bats (approximately $56 \%$, speciespoor Oceania excluded). Bats overall have fewer feeding guilds than birds, with no plant, seed, non-arthropod invertebrate, or carrion specialists. 


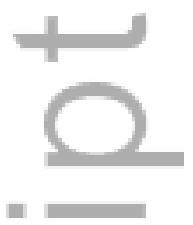

(3) Birds and bats in different land-use systems

Although few bird species prefer agricultural areas for feeding, breeding, and other activities, nearly a third of all bird species occasionally use such habitats ( ekercio lu et al., 2007), especially in combination with forests ( ekercio lu, 2012; Fig. 2). Compared to primary forests, species richness of large frugivorous and insectivorous birds often declines in agroforests (i.e. coffee, cacao, and mixed fruit orchard), particularly among terrestrial and understorey species. By contrast, nectarivores, small-to-medium insectivores (especially migrants and canopy species), omnivores, and some granivores and small frugivores have higher species richness in agroforests compared with forest habitats ( ekercio lu, 2012).

These global trends are supported by field research results from Afrotropical (Waltert et al., 2005), Indomalayan (Peh et al., 2006), Australasian (Marsden, Symes \& Mack, 2006), and Neotropical (Leyequien, de Boer \& Toledo, 2010) regions. In general, these field studies suggest that the replacement of forests with agricultural systems results in a shift towards less-specialized bird communities, comprised of more-widespread and relatively common species, and with altered proportions of functional groups (Karp et al., 2011; ekercio lu, 2012; Fig. 2). Specifically, agricultural systems harbour fewer insectivores and other invertebrate pest consumers but more seed predators (Tscharntke et al., 2008; ekercio lu, 2012).

Like birds, most bat species live in forests (Fig. 2), and about one quarter (246 species) occur exclusively there, yet bats are also well adapted to human landscapes. According to IUCN Red List data, almost a quarter of the world's bats (271 species) use agricultural habitats such as arable land, pastureland, and plantations (IUCN, 2014). Forest-agri bat communities (which we define as bats occurring both in forest and agricultural habitats) are also well represented with 
253 species, and have previously been shown to be successful in coffee and cacao agroforestry systems (Harvey \& Villalobos, 2007; Williams-Guillén \& Perfecto, 2010). In Costa Rica, for example, approximately $60 \%$ of bats surveyed in forest reserves and forest fragments were detected at least once in agricultural habitats (Mendenhall et al., 2014).

Across all habitat types, bat communities are dominated by insectivores (more than $60 \%$ of species) and frugivores (more than $20 \%$ ). It should be noted, however, that there are very few agricultural-specialist bats (bats using agricultural habitats but not forest; 11 species), making it difficult to detect shifts in feeding-guild structure across habitats analogously to those we observed for birds. Apart from the loss of vertebrate feeders, bat feeding guilds in forest-agri systems remain similar to forest bat feeding guilds. Note that evidence from the Paleotropics on the representation of different feeding guilds in forests and agricultural habitats is limited (e.g. Furey, Mackie \& Racey, 2010; Phommexay et al., 2011; in this review: 26 reports from the Neotropics versus six reports from the Paleotropics listed in Table S1), and additional investigations are needed to clarify if these results based largely on the Neotropics can be applied elsewhere.

\section{EFFECTS ON FOOD WEBS}

In temperate zones, predators affect plant communities by consuming herbivores, indirectly influencing plant community composition, age structure, diversity, crop yield, productivity, and even nutrient cycling (Letourneau et al., 2009). Such trophic cascades occur through a decrease in herbivorous arthropod abundance, reducing their negative effects on plants. Until recently, trophic cascades were thought to be rare in tropical terrestrial communities as a result of high species richness, including remarkable densities of insectivorous birds and bats 


\section{$+$ \\ (Polis \& Holt, 1992; Strong, 1992; Polis \& Strong, 1996). In theory, diverse and complex $=$}

predator-prey interaction networks should contain redundancy such that the loss of any individual predator guild would be compensated by functionally redundant species, thus preventing a trophic cascade. However, exclosure experiments have documented the presence of insectivorous bird-and bat-initiated trophic cascades in both natural and human-dominated tropical landscapes (Van Bael et al., 2008; Mooney et al., 2010; Mäntylä, Klemola \& Laaksonen, 2011).

Most exclosure experiments have been conducted in the Neotropics and the Caribbean (Van Bael et al., 2008), although top-down effects on arthropods by birds and bats have also been documented in Hawaii (Hooks, Pandey \& Johnson, 2003; Gruner, 2004, 2005; Gruner \& Taylor, 2006), Asia (Koh, 2010; Maas et al., 2013), Australia (Loyn, Runnalls \& Forward, 1983), and Africa (Dunham, 2008). Moreover, tropical trophic cascades have similar effect sizes as those in temperate and boreal systems (Mooney et al., 2010; Mäntylä et al., 2011; Morrison \& Lindell, 2012). However, the specific effects of birds and bats on arthropod communities might not be the same in different regions because of differences in species richness and specialization, necessitating additional research from underrepresented tropical areas such as the Paleotropics.

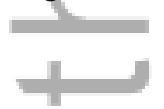

\section{(1) Bird and bat effects on arthropods and plants in tropical communities}

Birds and bats generally reduce total arthropod abundance and biomass in the tropics (Van Bael et al., 2008; Mooney et al., 2010; but see Van Bael, Brawn \& Robinson, 2003; Van Bael \& Brawn, 2005; Michel, 2012; Fig. 3), but they generally do not affect arthropod diversity (Mooney et al., 2010; but see Gruner \& Taylor, 2006). 
Bird and bat top-down effects often differ by arthropod size, with some indications that

birds - particularly breeding birds - consume larger arthropods than bats. Three studies have found that the effects of birds and bats combined reduced large arthropods ( $>5 \mathrm{~mm}$ or e $3 \mathrm{~mm}$ ) but not small arthropods ( $<2$ mm; Greenberg et al., 2000b; Borkhataria, Collazo \& Groom, 2006; Van Bael, Bichier \& Greenberg, 2007a). Conversely, Karp \& Daily (2014) found that birds reduced large and small arthropods while bats reduced only small arthropods, which they attributed to consumption of large arthropod larvae by birds but not bats. In Mexico, both birds and bats (separately and together) reduced both large and small arthropods (Williams-Guillén et al., 2008). In Jamaica, birds and bats reduced large arthropods in summer and autumn, but only reduced small arthropods in the summer (Johnson et al., 2009). This may be explained by the breeding currency hypothesis (Greenberg, 1995), which states that breeding resident birds take large arthropods suitable for nestlings ("breeding currency") during the breeding season (spring and summer), whereas in the autumn Nearctic migrants and non-breeding residents consume more small prey.

Birds and bats often reduce the abundance of leaf-chewing and phloem-feeding insects (Van Bael et al., 2008; Mooney et al., 2010), but the extent of limitation of these dominant pests often varies among study sites (Van Bael, Brawn \& Robinson, 2003; Van Bael \& Brawn, 2005; Michel, 2012; Michel, Sherry \& Carson, 2014) and insect orders (Van Bael et al., 2007a;

Williams-Guillén et al., 2008; Maas et al., 2013). Given the importance of herbivorous arthropod suppression for plant communities, including crops, further research into the factors underlying spatial and phylogenetic variation in bird and bat predation is encouraged. Moreover, birds and bats also frequently limit numbers of arthropod predators such as ants and spiders (Van Bael et al., 2008; Mooney et al., 2010; Mestre et al., 2013; Karp \& Daily, 2014; but see e.g. Borkhataria 


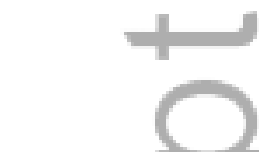

et al., 2006; Hooks et al., 2003; Maas et al., 2013; Michel et al., 2014; Fig. 3), potentially reducing top-down effects on herbivorous insect densities (Martin et al., 2013).

While rarely reported, birds and bats may suppress arthropod outbreaks in tropical communities. Birds and bats inhibited invasion by an introduced spider (Achaearanea riparia) in Hawaii (Gruner, 2005), and were observed consuming large quantities of caterpillars during an outbreak in Panama (Van Bael et al., 2004). Moreover, during an experimentally simulated outbreak, birds and bats substantially reduced the abundance of lepidopteran larvae in a Mexican shaded coffee plantation (Perfecto et al., 2004). These isolated experiments introduce the potential for widespread outbreak suppression.

Through preventing outbreaks and consuming herbivorous arthropods, birds and bats often indirectly affect plants, although these effects on plants are generally weaker than effects on arthropod abundances (Van Bael et al., 2008). Plant damage generally shows a stronger response to bird and bat exclusion than leaf biomass, plant growth, or reproductive output (e.g. fruit yield; Schmitz, Hambäck \& Beckermann, 2000; Van Bael et al., 2008; Mooney et al., 2010; Mäntylä et al.,2011; Morrison \& Lindell, 2012). However, birds and bats do not always protect plants, for reasons that remain unclear (see, e.g. Van Bael \& Brawn, 2005; Williams-Guillén et al., 2008; Morrison \& Lindell, 2012; Maas et al., 2013). Notably, leaf damage was actually greater in the presence of birds and bats outside experimental mammal exclosures at La Selva Biological Station in Costa Rica (Michel et al., 2014).

A potential limitation of exclosure experiments is that they likely underestimate bird and bat effects on arthropods, as many species capture insects in flight, distant from plants (or exclosures) (Kunz et al., 2011). In addition, the exclosure mesh size may potentially introduce a bias by hindering movement of larger arthropods (e.g. adult lepidopterans); few studies have 
analysed such cage-induced size biases (Van Bael \& Brawn, 2005; Gunnarsson, 2007; Maas et al., 2013). Nevertheless, studies to date indicate that birds and bats have strong and pervasive although variable - effects on arthropods and plants in tropical communities.

\section{(2) Factors influencing tropical trophic cascade strength}

The strength of top-down effects of bats and birds on tropical arthropods and plants can vary substantially. Below, we review insectivore, arthropod, plant, and community traits that could affect trophic cascade strength in the tropics.

\section{(a) Insectivore identity}

Early exclosure experiments in tropical communities attributed arthropod suppression and plant effects to insectivorous birds, overlooking or minimizing the potential effects of gleaning bats, which are abundant in tropical areas and eat similar types of arthropod prey (Kalka \& Kalko, 2006; Whelan et al., 2008; Kunz et al., 2011). Nevertheless, the relative impact of birds versus bats on the densities of arthropods in general and of specific arthropod groups could vary as a result of differences in anatomy, behaviour, and relative abundance. For example, many tropical herbivorous arthropods are largely nocturnal, presumably making them more vulnerable to bat predation (Kalka \& Kalko, 2006). In Panama, gleaning bats have a larger impact on arthropod abundances and leaf damage than do birds, saving an estimated 52,000 kg of leaves from herbivory annually (Kalka \& Kalko, 2006; Kalka et al., 2008). Other studies have demonstrated broadly similar impacts of birds and bats on arthropods and plants, although with sometimes differing effects by arthropod clade and season (Williams-Guillén et al., 2008; Morrison \& Lindell, 2012). In the Caribbean lowland forest of Costa Rica, bat predation effects 
on herbivorous arthropods exceed the effects of birds in areas where insectivorous birds have

declined, suggesting that bats may functionally compensate for decreasing top-down limitation of arthropods provided by birds (Michel, 2012).

\section{(b) Insectivore foraging strategy}

Bats and birds possess unique foraging traits that may affect herbivore suppression, indirect effects on plants, and the strength of trophic cascades in predator-herbivore food webs (Kéfi et al., 2012). Bats tend to be generalist predators, although different foraging strategies (e.g. gleaners versus hawkers) might result in different effects on arthropod densities (e.g. Kunz et al., 2011). By contrast, gleaning insectivorous birds often have specialized diets and/or foraging strategies (Sherry, 1984; Whelan et al., 2008). For example, specialized guilds such as bark-probers, leaf tossers, and ant followers are found only among birds. These specialists can have important effects on limiting arthropods unavailable to generalist predators (e.g. barkprobing birds such as woodpeckers suppress wood-boring pests in temperate forest; see Fayt, Machmer \& Steeger, 2005; Koenig et al., 2013; Flower et al., 2014). On the other hand, generalist predators sometimes have stronger top-down effects than specialists (Halaj \& Wise, 2001; but see Symondson, Sunderland \& Greenstone, 2002; Borer et al., 2005).

Thus far we have discussed how birds and bats benefit plants by reducing the density of herbivorous arthropods, known as density-mediated effects. However, birds and bats may also benefit plants by inducing effects on phenotypic traits of prey such as mobility, dispersal propensity and feeding activity (trait-mediated effects; Werner \& Peacor, 2003). Indeed, traitmediated effects can involve changes in the foraging habits of herbivorous prey, potentially causing host shifts that differentially affect plant species (Calcagno et al., 2011) Even though 


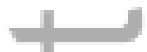

(2)

systematic research about trait-mediated effects of birds and bats on their prey is lacking, it =

seems that both bats and birds impose trait-mediated effects on arthropods with varying importance for arthropod suppression in different systems. For example, ultrasonic bat calls invoke behavioural responses in insects that alter insect infestation rates, mating behaviour, and reproductive success (Kunz et al., 2011), while birds can affect the foraging pattern of aphidtending ants in tree canopies (Mooney \& Linhart, 2006). The relationship between bird and bat foraging strategies and the abundance of certain arthropod groups that differ in abundance and overall impact on plant productivity might explain their different relative impacts on pest control, plant growth and crop yields in the different land-use systems and tropical landscapes that have been investigated to date.

\section{(c) Insectivore diversity and abundance}

Diversity and abundance of predators may either strengthen or weaken trophic cascade effects, depending on the nature of intraguild interactions. The species-complementarity model suggests that insectivore richness increases herbivore suppression through additive or synergistic effects (Tscharntke et al., 2005; Classen et al., 2014). For example, birds in mixed-species foraging flocks often eat arthropods flushed out by other species, thus potentially consuming more arthropods collectively (synergistic effects) than the sum of the arthropods consumed by each species independently (additive effects; Munn \& Terborgh, 1979). The sampling-effects model posits that more-diverse communities will have an increased probability of containing a highly effective insectivore (e.g. Huston, 1997; Schmitz, 2007). Conversely, the selection-effects model predicts that the probability of a disruptive species (i.e. a species that interacts negatively 


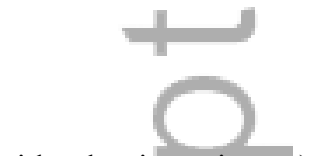

with other insectivores) increases with insectivore richness, thus weakening herbivore

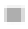
suppression (antagonistic effects; Letourneau et al., 2009).

A global meta-analysis of arthropod herbivore suppression in terrestrial ecosystems demonstrated that herbivore suppression increased with enemy (predator and parasitoid) richness in 183 of 266 experiments, while suppression decreased with enemy richness in 80 comparisons (Letourneau et al., 2009; see also Michel, 2012; Ruiz-Guerra, Renton \& Dirzo, 2012). Besides species richness, functional richness (number of functional groups), richness of a few important functional groups (e.g. small understorey foliage-gleaning insectivores), and the presence of a highly efficient avian insectivore (Oreothlypis peregrina) also increased top-down effects in tropical cacao and coffee agroforests (Philpott et al., 2009). Moreover, predation on a simulated caterpillar outbreak was significantly greater in a diverse shade coffee system with a diverse and abundant insectivorous bird community than a monodominant system with lower avian diversity (Perfecto et al., 2004). The degree to which species richness affects top-down control by bats is essentially unknown, primarily because of the difficulties in adequately sampling bat communities: commonly used capture methods such as mist netting lead to substantial underestimation of the richness and abundance of insectivorous bats in tropical communities (MacSwiney et al., 2008; Williams-Guillén \& Perfecto, 2011), since many insectivores have well-developed echolocation calls that allow them to avoid nets.

In addition to bolstering arthropod suppression, increasing bird and bat diversity could also affect the stability of arthropod suppression through ensuring that bird and bat abundances remain constant over time. The insurance hypothesis (Yachi \& Loreau, 1999) posits that high predator diversity may ensure continued ecosystem functioning in the presence of environmental fluctuations or perturbations (e.g. by limiting pest outbreaks and/or contributing to long-term 


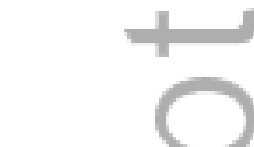

yields). One explanation for this phenomenon is the portfolio effect, which posits that a statistical consequence of many species fluctuating in abundance is that total abundance can remain constant (Doak et al., 1998). Alternatively, more diverse communities could be more stable because they contain many competitors: if one species declines, then its competitor may exhibit density compensation and rapidly increase in abundance. Regardless of mechanism, more-diverse tropical insectivorous bird communities have been shown to be more stable (Karp et al., 2011). A critical remaining question, however, is whether diverse, stable bird and bat communities also suppress arthropod abundances more consistently over time than communities that fluctuate in total bird and bat abundance.

\section{(d) Presence of migratory birds}

Top-down effects on arthropods are typically greater in tropical natural forests and agroforests when migrant birds are present (Van Bael et al., 2008; Williams-Guillén et al., 2008; Michel, 2012). Nearctic-Neotropical migrant birds (e.g. flycatchers, warblers) are largely insectivorous; for example, 29 of the 35 northern migrants on Barro Colorado Island, Panama, are insectivorous or omnivorous (Sigel, Robinson \& Sherry, 2010). Moreover, Nearctic migrants may double insectivorous bird abundance in Neotropical forests during the northern winter, which overlaps with the tropical dry season when arthropod abundance is often low and, consequently, birds consume a larger proportion of the available arthropods (Van Bael et al., 2008). Indeed, the relative importance of bird versus bat-mediated arthropod consumption was higher when migratory birds were present in Mexican coffee landscapes (Williams-Guillén et al., 2008). However, top-down effects on arthropods were greater when migrants were absent in a different study excluding both birds and bats from shade tree branches at the same site, perhaps 
due to the greater energetic needs of resident breeding birds (Philpott et al., 2004). The effects of<smiles>[CH]=[CH]</smiles>

migrant birds on arthropod suppression are thus unresolved.

\section{(e) Intraguild predation}

Intraguild predation is a form of trophic omnivory that occurs when predators consume other predators, and may be unidirectional (top predator consumes intermediate predator) or mutual (predators consume one another). Intermediate predators are predicted to be more effective than top predators at suppressing shared prey when intraguild predation is unidirectional, as is the case with birds, bats, and arthropod predators (Vance-Chalcraft et al., 2007). Consequently, intraguild predation of birds and bats on arthropod predators is expected to reduce herbivorous arthropod suppression and dampen the strength of trophic cascades (Tscharntke, 1997; Finke \& Denno, 2005; Martin et al., 2013). However, a recent meta-analysis showed that the effects of vertebrate insectivores on herbivores and plants were strongest in systems with strong intraguild predation and weak trophic cascade strength (Mooney et al., 2010). Insectivorous birds and bats with relatively large body sizes, high mobility, and sophisticated foraging strategies- particularly generalists - may be able to switch dynamically between arthropod predators and herbivores as availability allows, thus maintaining their role as top predators and indirectly suppressing leaf damage (Mooney et al., 2010).

\section{(f) Herbivore diversity}

Arthropod community composition may also influence trophic cascade strength. In systems with high herbivore diversity, trophic cascades - including indirect effects on plants are generally weaker (Schmitz et al., 2000). Indeed, Van Bael \& Brawn (2005) found stronger 


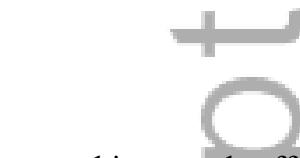

trophic cascade effects in seasonal forest, with lower herbivore diversity, than in moist forest during the dry season. In addition, fluctuations in arthropod abundances are often related to seasonal patterns (Janzen \& Schoener, 1968), which likely affect the foraging behaviour of birds and bats (see Section V.2), and consequently trophic cascade strength.

\section{(g) Productivity}

Systems with high primary productivity may have higher intermediate and top predator abundance and, consequently, stronger trophic cascades (Kagata \& Ohgushi, 2006; Mooney et al., 2010). Herbivore reduction was stronger in areas of higher productivity (forest canopy versus understorey, seasonal versus moist forest) in Panama (Van Bael \& Brawn, 2005). However, other tropical studies found that top-down effects on herbivorous arthropods and leaf damage were either unaffected by productivity (Greenberg et al., 2000a; Philpott et al., 2009; Mooney et al., 2010) or were weaker in the higher-productivity environment (Greenberg \& Ortiz, 1994). The effect of primary productivity on trophic cascade strength in tropical communities also remains unclear.

(h) Plant ontogeny and defences

Young plants may allocate more resources to growth than anti-herbivore defences, while mature plants produce fewer but better defended leaves. Indeed, most tropical herbivory occurs when leaves are young (Coley \& Barone, 1996), so trophic cascades may weaken as plants mature (Boege \& Marquis, 2006). Strong anti-herbivore defences were associated with attenuation of trophic cascades in temperate systems (Schmitz et al., 2000). However, two meta- 
analyses of tropical and temperate exclosure studies found similar effect sizes for saplings versus mature plants (Mooney et al., 2010; Mäntylä et al., 2011).

\section{(i) Natural versus agricultural systems}

Agroforests such as coffee, cacao and mixed fruit orchard plantations differ from natural forests in many of the characteristics described above. Neotropical agroforest communities generally have lower insectivore and plant species richness and a higher degree of omnivory (Figs 1 and 2; Tejada-Cruz \& Sutherland, 2004; Van Bael et al., 2008; ekercio lu, 2012; but see Maas et al., 2013), both of which may reduce trophic cascade strength. However, agroforests are home to many Nearctic bird migrants, and may have lower herbivore diversity, higher productivity, and a higher proportion of young plants, with variable effects on the strength of trophic cascades. These contrasting factors complicate prediction of trophic cascade strength in natural versus agricultural tropical communities. It is clear, however, that bird- and bat-mediated trophic cascades occur regularly in agricultural settings, potentially resulting in depressed pest abundances and increased yields for farmers (e.g. Maas et al., 2013; Kellerman et al., 2008; Johnson et al., 2010, Karp et al., 2013).

\section{BIRD AND BAT SERVICES IN AGRICULTURAL SYSTEMS}

Predation by birds and bats constitutes an ecosystem service when it reduces arthropods that are herbivores on crops; often referred to as biological control. Moreover, limitation of herbivore populations may also have positive effects on the health of crop plants, since arthropod herbivores can vector crop diseases (Campbell, 1983; Evans, 2007; Wielgoss et al., 2012, 2014). Until recently, the relative importance of birds versus bats as predators of pests was unknown, as 
exclosure experiments confounded bird and bat predation, even if bird predation was stressed as a key factor (Kalka et al., 2008; Williams-Guillén et al., 2008; Koh, 2010; Morrison \& Lindell, 2012).

With the advent of molecular techniques such as quantitative polymerase chain reaction (qPCR) and next-generation sequencing (NGS), several recent studies have demonstrated the prevalence of significant arthropod crop pest species in the diet of bats roosting and foraging in a range of agroecosystems (Cleveland et al., 2006; Whitaker, McCracken \& Siemers, 2009; Brown, 2010; Clare et al., 2011; Kunz et al., 2011; Bohmann et al., 2011; McCracken et al., 2012; Taylor et al., 2013a).

\section{(1) Bird and bat predation in tropical agroforestry}

Given the potential that bats also limit pests, recent exclosure studies have sought to disentangle the effects of birds and bats on arthropods in agricultural systems (Williams-Guillén et al., 2008; Maas et al., 2013; Karp \& Daily, 2014). Williams-Guillén et al. (2008) showed that the effect of bats in reducing overall arthropod abundance in Mexican coffee plantations was greater than the effect of birds ( $84 \%$ versus $58 \%$, respectively) during the wet season. By contrast, in the dry season when migrant birds were present, birds reduced total arthropod abundance more than bats ( $30 \%$ versus $6 \%$, respectively). Recent studies in Indonesian cacao (Maas et al., 2013) and Costa Rican coffee plantations (Karp \& Daily, 2014) also demonstrated differential effects of birds and bats, although with sometimes conflicting results. Bats appeared to have a greater impact than birds in Indonesian cacao farms (Maas et al., 2013). By contrast, in Costa Rican coffee farms, birds accounted for the majority of the reduction in abundance of the coffee berry borer (Hypothenemus hampei) (Karp et al., 2013). Thus, the few studies that have 


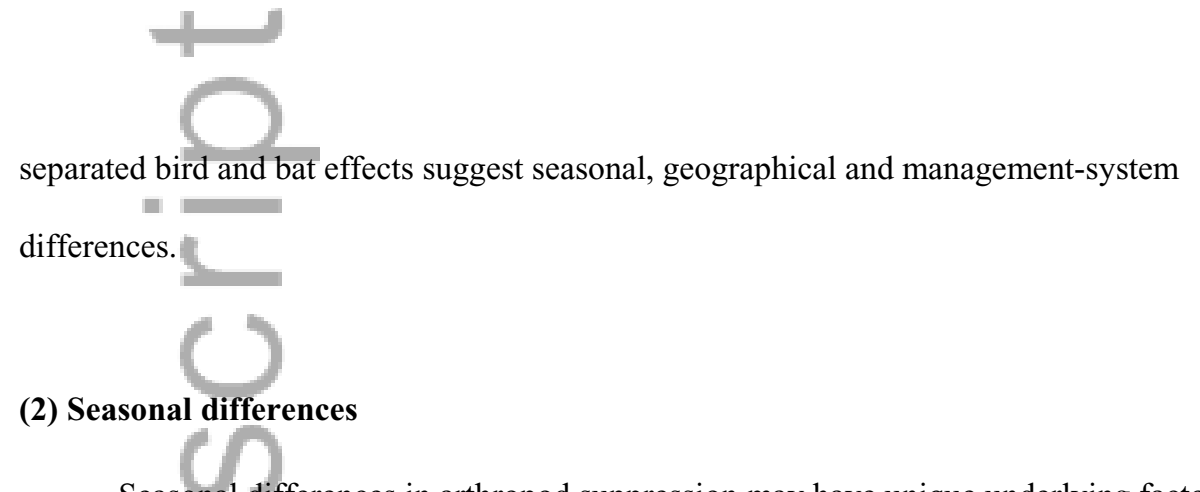

Seasonal differences in arthropod suppression may have unique underlying factors for birds compared to bats. As discussed in Section IV, seasonal variability in bird effects is likely due to influxes of migrant birds in tropical agroforests (Greenberg et al., 2000a; WilliamsGuillén et al., 2008). Although bats may be resident year-round, insectivorous bats can be opportunistic predators, and many Neotropical bat species are seasonal omnivores (Patterson, Pacheco \& Solari, 1996). For bats, seasonality in feeding behaviour is likely to be due to changes in metabolic requirements in the breeding season. The effects of bats are thought to be stronger when they are breeding (Williams-Guillén et al., 2008; Singer et al., 2012) because of substantial increases in basal metabolism and insect consumption by pregnant and lactating bats (Kunz, Whitaker \& Wadanoli, 1995). Tropical birds that feed only on few or no insects during the nonbreeding season are also known to increase their insect intake or to add arthropod prey to their diet during the breeding season - seasonal feeding behaviour that has been described by the protein-limitation hypothesis (Cox, 1985). Strict insectivores may also switch to eating larger and softer-bodied prey during the breeding season, including chewing herbivores such as Lepidoptera larvae, as described by the breeding-currency hypothesis (Greenberg, 1995). Changes in the composition and quality of bird diets can also be linked to seasonal temperature fluctuations, migration, and seasonal changes in food availability (Whelan et al., 2000).

The foraging behaviour of birds and bats is also likely influenced by fluctuating arthropod numbers (see Section IV.2c), which tend to be pronounced under more-extreme seasonal rainfall 
conditions (Janzen \& Schoener, 1968). Since many bats are opportunistic predators, their foraging activity in a particular agroecosystem may coincide with annual peaks in abundance of the primary pests in that system (Taylor et al., 2013b).

\section{(3) Zoogeographic patterns}

Zoogeographic patterns are likely also to be key factors in regulating the strength of bird and bat effects on arthropod communities. While one study observed 188 bird species foraging in Central American cacao farms [abundance-based coverage estimation (ACE) indicated inventory completeness of 74\%; Van Bael et al., 2007b), a study in cacao farms of Sulawesi found only 69 bird species (ACE indicated inventory completeness of 79\%; Maas et al., 2015). Similarly, in the Neotropics, foliage-gleaning bats include a wide range of arthropod types in their diet (Kalka \& Kalko, 2006). In a study of Neotropical bats foraging in cacao farms, insectivorous foliage gleaners were the second most-species-rich feeding guild (Faria et al., 2006). By contrast, species richness of insectivorous foliage gleaners and activity of insectivorous bats declined greatly in several agriculture systems in Southeast Asia (Furey et al., 2010; Phommexay et al., 2011). Given the differences in species diversity and results on arthropod suppression, there may be a greater number of bat species preying on more types of arthropods in agroforests of the Neotropics relative to the Paleotropics. However, bat species diversity is poorly resolved for most sites, making zoogeographic comparisons difficult. 


\section{(4) Effects on leaf damage and crop yield}

Whether birds and bats provide arthropod suppression services to farmers depends on whether their predation on arthropods results in reduced plant damage and higher crop yields. Across seven coffee and cacao studies, bird and bat predation combined reduced leaf damage significantly (Van Bael et al., 2008). By contrast, some other studies did not find significant effects on leaf damage (Williams-Guillén et al., 2008; Maas et al., 2013). One study measured yield changes directly and found a $31 \%$ reduction in yield when birds and bats combined were prevented from foraging on cacao trees; constituting an estimated loss of US $\$ 730 /$ ha (Maas et al., 2013). Similarly, several studies documented that birds reduce coffee berry borer beetle (Hypothemus hampei) abundance and improve yields. Borer consumption saved farmers US $\$ 310 /$ ha as a result of reduced coffee yield loss in one Jamaican plantation, US $\$ 44-105 /$ ha in several other Jamaican plantations, and US \$75-310 in Costa Rican coffee plantations (Kellerman et al., 2008; Johnson et al., 2010; Karp et al., 2013). Most of these studies focused only on bird effects, neglecting the critical role of insectivorous bats (but see Maas et al., 2013; Karp et al., 2013). For example, in Thailand, a single common bat species recently has been estimated to prevent rice (Oryza sativa) loss from planthopper pests of almost 2,900 tons per year, which translates into a national economic value of more than US $\$ 1.2$ million or rice meals for almost 26,200 people annually (Wanger et al., 2014).

As outlined in Section IV.2e, whether or not the suppression of arthropods (biological control) occurs may depend on the identity of the arthropod feeding guilds that are suppressed by birds and bats; specifically, whether birds or bats feed as intraguild predators. Since birds and bats consume spiders, and spiders consume herbivorous or pest insect taxa such as lepidopteran larvae (Hooks, Pandey \& Johnson, 2006), some herbivorous pests could be released from spider 
predation as a result of bird and bat feeding activity. In Indonesian cacao plantations, birds and bats consumed both herbivores and spiders and therefore prevented crop damage, without having significant effects on crop diseases or leaf damage (Maas et al., 2013). One recent study in coffee, however, found that birds reduced herbivores and leaf damage, while bats primarily reduced spiders and did not affect leaf damage (Karp \& Daily, 2014).

\section{(5) Pollination services and crop yield}

While birds and bats are efficient predators in many agroecosystems, in some settings bats also play an important role as pollinators, thereby also directly impacting crop yields. In Southeast Asia, nectarivorous bats and fruit bats are pollinators of petai (Parkia spp.), durian (Durio spp.) and Indian trumpet (Oroxylum indicum), common economically important plants in agroforestry. Bat pollination accounts for $80-100 \%$ in fruit set in these crops (Bumrungsri et al., 2008, 2009; Srithongchuay, Bumrungsri \& Sripao-Raya, 2008). In southern Thailand alone, such pollination services to durian and petai were estimated to be worth US \$13 million annually (Bumrungsri et al., 2009). Indirect interactions that impact pollination could also occur; for example, if bird and/or bat predation reduces arthropods that pollinate flowers (Maas et al., 2013). No evidence of this was observed in a recent study of vertebrate predator and pollinator interactions for coffee, rather these ecosystem services were complementary (Classen et al., 2014).

\section{LOCAL AND LANDSCAPE-MANAGEMENT EFFECTS}

The ecological services provided by birds and bats, including pest suppression and indirect benefits to crop yield (see Section V), are not distributed homogenously across space as a 
result of changes in the abundance, diversity, and composition of species. Local and landscapelevel habitat characteristics have important consequences for the predatory services provided by many species and functional guilds that have particular habitat requirements (see Section III). Tropical agroforests vary in local vegetation characteristics such as shade, tree density, diversity, and height that modify the local environment from forest-like to open-sun habitat (Perfecto et al., 1996; Moguel \& Toledo, 1999). Tropical landscapes also vary in relative proportions of continuous forest, fragmented forest, agriculture, and urban land uses (Clough et al., 2009a; Karp et al., 2013). To date, few studies have experimentally excluded birds and bats to assess the influence of local and landscape features on ecosystem functioning.

\section{(1) Local effects on predatory function}

Bird and bat biodiversity and abundance typically declines as agroforestry systems change from high to low shade in coffee (Greenberg, Bichier \& Sterling, 1997b; Philpott et al., 2008; Williams-Guillén \& Perfecto, 2010, 2011), cacao (Faria et al., 2006; Van Bael et al., 2007b), and pastoral systems (Greenberg, Bichlier \& Sterling, 1997a). Yet bird and bat exclosure experiments replicated across shade gradients reveal mixed results. In coffee, Perfecto et al. (2004) found greater predation of lepidopteran larvae and Johnson et al. (2009) found reduced leaf damage in high-shade relative to low-shade sites. However, Kellermann et al. (2008) and Greenberg et al. (2000a) found that shade management did not affect predation rates. Further, Johnson et al. (2010) found greater predation of the coffee berry borer in sunny relative to shady plantations. Only one study has focused on cacao, where no differences in bird and bat effects were observed across a shade gradient in Indonesia, except for lepidopteran larvae, which increased in abundance in response to bird and bat exclosures in cacao plantations with a higher 
shade cover (Maas et al., 2013). Larger forest restoration plantings showed cascading effects of bird and bat presence on leaf damage; smaller plantings did not show reduced leaf damage although patterns were in the same direction as for larger plantings (Morrison \& Lindell, 2012). Other common agricultural practices, such as the use of fertilizers, insecticides, tillage, and irrigation may affect bird and bat communities (e.g. Geluso, Aletnbach \& Wilson, 1976; Kunz, Anthony \& Rumage, 1977; Senthilkumar et al., 2001; Hallmann et al., 2014), but few studies have yet assessed these practices in tropical regions. Additionally, changes to local management of other agroforestry systems, including diverse home gardens and shaded pasturelands (agrosilvopastoral systems) may influence bird and bat predatory effects, but few have studied these changes.

\section{(2) Landscape effects on predatory function}

Complex landscapes with a high proportion of natural habitat may enhance pestsuppression services by increasing the diversity and abundance of natural predators (Bianchi et $a l ., 2006)$. Indeed, in tropical regions, bird and bat biodiversity generally increases with forest cover and connectivity (Faria et al., 2006; Harvey et al., 2006; Harvey \& Villalobos, 2007). Intact forests and more-diversified agriculture may also confer resilience and stability to tropical bird communities (Karp et al., 2011).

To date, few studies have excluded birds and bats along landscape complexity gradients (Tscharntke et al., 2012b). Karp et al. (2013), however, found greater effects of birds on the coffee berry borer near forest fragments, but did not find effects of bats. Johnson et al. (2009) found greater reductions in coffee leaf damage at greater distances from habitat patches and Kellermann et al. (2008) found no relationship between distance to habitat patch and predation of 


\begin{abstract}
the coffee berry borer. Maas et al. (2013) also evaluated effects of bird and bat predation in cacao plantations along a distance gradient from primary forest, but found no landscape effect on overall arthropod density or herbivory, with the only exception represented by lepidopteran larvae, which increased in abundance at higher distances to primary forest. Studies investigating naturally forested landscapes in France and New Zealand found enhanced avian attack of plasticine larval models near forest edges relative to forest interiors (Barbaro et al., 2014). However, landscape diversity (amount of different forest and open-land habitats) and native forest cover did not correlate with predation rates. Further, Michel (2012) compared bird and bat exclosures in a fragmented forest in Costa Rica and a continuous forest in Nicaragua, finding that birds suppressed herbivory to a greater degree than did bats in the continuous forest with intact bird communities, whereas bats suppressed herbivory to a greater degree than did birds in fragmented forest with depauperate bird communities.
\end{abstract}

The field experiments described above indicate some dependence of pest suppression services on the landscape context. Due to the ability to control more variables, simulation models may provide additional insight into the effects of landscape context on biological control. A

recent attempt to model the effects of 'land sharing' (e.g. shade-grown coffee) and 'land sparing' (e.g. monoculture next to forest) on bird-mediated coffee borer beetle suppression revealed that trees and forest fragments were more important for suppression than intact forest (Railsback \& Johnson, 2014). Indeed pest suppression by birds peaked when only $5 \%$ of the area was occupied by trees and forest fragments. While intact forest supported higher bird densities in their model, birds had to return to the forest nightly and did not move far enough from the forest in the course of a day to forage on pests across the entire area. 


\section{Drivers of local and landscape effects}

Despite limited evidence that bird and bat predatory function is dependent on local and landscape factors, there are many reasons to expect context dependency. Compared to non-volant vertebrates with similar body sizes, many bird and especially bat species are relatively mobile and capable of foraging over both small and large spatio-temporal scales (Kunz et al., 2011; Lundberg \& Moberg, 2003; Whelan et al., 2008; but see Moore et al., 2008). This is particularly true for habitat generalists because their movements are not restricted by specific habitat types and allow them to cross complex landscapes. Hence, landscape context may be important when considering the conservation and management of bird- and bat-mediated ecosystem functions (Cleveland et al., 2006; Polis, Anderson \& Holt, 1997; Struebig et al., 2009). On the other hand, some species are habitat specialists and dispersal limited (Moore et al., 2008), and therefore any reductions in habitat quality will reduce their abundance and predatory services.

In addition to mobility, a number of functional traits including foraging mode, migration, trophic niche, nesting or roosting ecology, and body mass vary across bird and bat species (Fleming \& Eby, 2005; Kunz \& Lumsden, 2005; Patterson, Willig \& Stevens, 2005). These traits are associated with bird and bat responses to changes in local vegetation structure and land-use change and therefore could help predict changes in pest-suppression services (Clough et al., 2009a; Flynn et al., 2009; Maas et al., 2009; Williams-Guillén \& Perfecto, 2010, 2011).

Nesting and roosting life-history characteristics may be key to understanding the importance of local and landscape-scale habitat alterations to vertebrate functions (Tscharntke $e t$ al., 2005). Species that nest or roost exclusively on plants are expected to be more sensitive to local habitat quality, while cliff nesting and cave roosting species are expected to be less sensitive to vegetation modification (Kingston, 2013). For example, investigations of a 


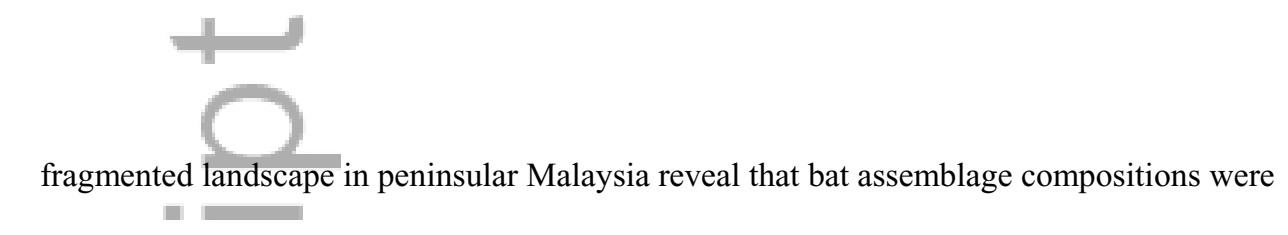
driven by the abundance of cave bats, which was associated with distance to karst outcrops, but less with patch size and isolation (Struebig et al., 2009). By contrast, Struebig et al. (2013) report a positive relationship between the abundance of forest bats and cavity numbers in repeatedly logged rainforest landscapes.

In regions where millions of bats occupy cave roost colonies, such as, for example, in Texas (McCracken et al., 2012) and Thailand (Wanger et al., 2014), it has been possible to derive pest-suppression estimates for agroecosystems in the foraging range of these bats.

However, it is possible that the pest-suppression estimates in such cases might be inflated. Future research should investigate the landscape effects on pest suppression of very large roosts compared to areas where bats are more dispersed in the landscape, occupying many smaller roosts.

Information on roosting behaviour and roost restoration for tropical birds is highly limited. A recent study from Jamaican coffee farms (Railsback \& Johnson, 2014) emphasizes the importance of nighttime roosting for birds. Accordingly, the availability of trees suitable as foraging or roosting sites for birds near coffee plantations enhanced the efficiency of arthropod suppression by birds, while the dispersion of trees within coffee farms did not affect those services.

Habitat loss and fragmentation may also alter behavioural traits associated with the movement and migration of birds and bats (Béchet et al., 2003; Bélisle, Desrochers \& Fortin, 2001), which could lead to losses of local populations and ecosystem functions in recipient habitats (Leibold et al., 2004; Bregman, ekercio lu \& Tobias, 2014). A recent study from the cacao-dominated and highly dynamic forest margin landscape of Central Sulawesi highlights the 
critical role of rapid forest tree declines on native forest bird diversity, documenting the collapse of an endemic bird population (Maas et al., 2013).

\section{KNOWLEDGE GAPS AND NEED FOR FURTHER STUDIES}

Many hypotheses have been proposed to explain variability in bird- and bat-mediated control of insect populations, but few have been evaluated. For example, the effects of herbivore diversity and primary productivity on bird and bat impacts on plants remain unclear. Moreover, basic natural history is missing for many tropical species, precluding our ability to account for spatial variation in pest control. For example, zoogeographic comparisons are complicated by missing information on the taxonomic structure of bat communities and bat species traits.

While we were able to provide an overview of the available literature on pest-suppression services of bats and birds across the tropics, including global distribution patterns of feeding guilds and habitat affiliations, our work demonstrated that there is a lack of systematic comparisons of the structure and trophic positioning between bat and bird communities. Furthermore, a greater emphasis on how roosting and nesting resources in focal and neighbouring habitats affects predatory functions could reveal whether these resources are strong drivers of arthropod suppression. Particularly for tropical birds, understanding of roosting behaviour and corresponding effects on ecosystem services and their management are highly limited. A better understanding of arthropod community structure and population dynamics in tropical agroforestry systems would significantly contribute to the quality of ecosystem research on birds and bats. In this context, the focus should be on underrepresented species groups, such as bats (especially in the Paleotropics) and abundant arthropods with high total biomass (e.g. Orthoptera, aphids, ants). 
With respect to the control of insect pests in tropical agricultural systems, there are several key questions and considerations that should be addressed in future studies. First, are the predation services of bats and birds of equal importance in different types of agricultural systems, in different zoogeographic regions, and in different land-use systems? Second, are there consistent, predictable differences in the effects of birds and bats on arthropods, multitrophic interactions and crop yield? Third, are there specific characteristics of birds and bats that determine their importance for ecosystem services (see Philpott et al., 2009)? For example, do generalists or specialist species perform these functions, and are these species rare or abundant? In this context, we also need to understand bird and bat responses to environmental factors such as habitat transformation, land-use intensification and climate change.

Finally, are insectivorous birds and bats functionally redundant? Understorey insectivorous birds are declining in both Neotropical and Paleotropical forests (^ekercio lu et al., 2002; Newmark, 2006, Sigel et al., 2010; Yong et al., 2011). Insectivorous bird loss may release herbivorous arthropods from predation with potentially devastating consequences for plant communities if other insectivores, including bats, are not able to compensate (Michel, 2012). Further study into compensatory effects of insectivorous birds and bats is urgently needed.

Few studies have assessed the importance of species-specific effects (e.g. in relation to abundance, traits, consumption rates or habitat preferences) and multitrophic interactions mediated by bird and bat predation (Philpott et al., 2009; Maas et al., 2013). These complex interactions between birds, bats and other natural enemies (e.g. ants and spiders) of leaf-chewing insects are likely jointly to affect the productivity of agricultural systems and therefore need to be considered simultaneously at different temporal and spatial scales and with careful consideration of the methods used. For example, bird and bat predation effects on spiders show contrasting 
results in different exclosure studies (e.g. Van Bael et al., 2008; Mooney et al., 2010; Mestre et

al., 2012, 2013; Karp \& Daily, 2014; Borkhataria et al., 2006; Hooks et al., 2003; Maas et al., 2013; Michelet al., 2014). This might be explained by the presence of different species-specific, local management, or geographic effects but could also be a result of enhanced spider abundances in experimental exclosures (e.g. web-building spiders might use exclosure nets as additional structures; Gunnarsson, 2007). The interactions between birds, bats and (predatory) ants are also poorly understood but very important given the strong evidence that their interactions drive the abundance of serious pest insect groups and crop yield in different agricultural systems throughout the tropics (Philpott, Greenberg \& Bichier, 2005; Wielgoss et al., 2012, 2014).

Most fundamentally, we need applied research that explores the practicalities of how growers can manage their farms to facilitate bird- and bat-mediated suppression of pest insects. Are there specific land-use patterns that promote ecosystem services by birds and bats (Clough et al., 2009a; Perfecto et al., 2004)? The literature suggests that bird and bat predatory effects may depend on local management practices and the landscape context, but results are inconsistent and provide little basis to draw general conclusions. Only a few studies, for example, have assessed the extent to which agricultural intensification affects pest consumption by birds and/or bats (Williams-Guillén \& Perfecto, 2010; Karp et al., 2013; Maas et al., 2013).

In order to understand the landscape-scale effects of birds and bats on tropical arthropod and plant communities, we must first understand the suite of factors influencing tropical insectivorous bird and bat abundance and richness patterns. In this context, information on factors such as effects of deforestation (Struebig et al., 2008, 2009), habitat degradation (Mendenhall et al., 2014), land-use intensification (Melo et al., 2013; Laurance et al., 2014) and 


\section{climate change (Urban et al., 2013) appear to be particularly limited. An improved understanding of the effects of environmental factors on bird and bat communities is needed to provide evidence-based management strategies for processes such as shifting food resources (Barber et al., 2008; Richter \& Cumming, 2008; McCracken et al., 2012), migration patterns (Béchet et al., 2003), transport of nutrients and energy (Whelan et al., 2008; Kunz et al., 2011) and altered proportions of functional groups of birds and bats (Hansen et al., 2001; Erasmus et al., 2002; Maas et al., 2009; ekercio lu, 2012). \\ Future experiments should be conducted to determine the single and combined effects of}

birds and bats on agricultural crop production and how these functions relate to specific local management practices (e.g. plant species diversity and composition; shade cover; herb layer) and landscape context (e.g. connectivity; surrounding forest cover). Such work should test hypotheses about the impacts of landscape moderation on ecosystem patterns and processes (Tscharntke et al., 2012b). Differences in species richness and functional diversity of birds and bats between different zoogeographic regions mean that management recommendations might not be transferable from one biogeographic region to another, increasing the need for studies conducted at landscape scales and specifically measuring the interactions between different taxa.

At a more practical level, studies on particular management practices that can enhance bird and bat ecosystem services are needed. In particular, evaluating the effects of restoration efforts on predatory function at different spatial scales may be of practical value for managers. For example, farmers would benefit from knowing whether restoring roost sites or adding nesting boxes could facilitate the ecological services of birds and bats (Kelm, Wiesner \& von Helversen, 2008). As a method to increase bat populations locally by artificially increasing the number of available roosts, bat houses have been used very successfully in North America (Tuttle, Kiser \& 


\section{$+1$ \\ Kiser, 2005; www.batcon.org) and in the Mediterranean area (Flaquer, Torre \& Ruiz-Jarillo,}

2006). Anecdotal evidence suggests that bat houses may assist with the control of crop pests, as in the case of an organic pecan nut orchard in Georgia, USA, where the addition of 13 bat houses led to a colony of some 3000 bats. Prior to the bat houses being installed, hickory shuckworms were damaging more than $30 \%$ of the crop, whereas after the successful occupation of bat houses, crop losses due to shuckworm damage became negligible (Kiser, 2002).

Evidence on the importance of bats in multitrophic food webs and the suppression of arthropods is limited, especially compared to the available number of studies on birds. However, existing results have led to several hypotheses concerning bats. For example, compared to birds, bats may (1) feed more often as generalist predators, (2) occupy a broader range of habitats, (3) be less speciose than birds (given their overall lower species richness), and (4) demonstrate lower sensitivity to seasonal influxes in migrant populations. These hypotheses lead to the conclusion that bat effects might be less variable across seasons and habitat types than birds, which could suggest that bat management involves fewer considerations than bird management.

Therefore further bat research may be particularly important not just from the perspective of limited knowledge of bats compared to birds, but also because improved understanding of bat effects on trophic cascades (as well as the impact of different management regimes and multitrophic interactions) might be the key to making progress towards profitable biodiversityfriendly management in tropical agriculture.

\section{MANAGEMENT OF BIRD AND BAT ECOSYSTEM SERVICES}

More studies that demonstrate the value of bird and bat pest-predation services could help promote the conservation of birds, bats, and other associated species. Specifically, vertebrate- 
mediated pest control could provide incentives for conserving source patches including caves, intact forest and high-quality matrices between source patches such as corridors, night roosts, forest remnants, and diverse agroforests (Jirinec, Campos \& Johnson, 2011; Wanger et al., 2014). No studies have evaluated how hunting pressure affects predatory function, but incentives to curtail hunting could exist if it lowers the number of individuals arriving at recipient habitats and indirectly shifts migration patterns (Béchet et al., 2003). Hunting effects on insectivorous birds and bats might be of higher importance in the Paleotropics, where hunting also affects large numbers of smaller species, partly due to limited law enforcement, traditional hunting practices (for food and/or medicine) and the growing market for rare species that are traded as pets (Bennett et al., 2006; Nijman, 2010; Wiles et al., 2010; Scheffers et al., 2012). On the other hand, smallholder agroforests with a diverse shade tree cover have been shown to support substantially higher levels of species richness and functional diversity than intensified land-use systems, which may enhance the natural ecosystem services provided by birds and bats (Tscharntke et al., 2005; Whelan et al., 2008; Kunz et al., 2011). The proximity of forest also seems to support avian predatory function (Clough et al., 2009a; Karp et al., 2013; Maas et al., 2015) although data on bat predation are lacking. Moreover, agroforestry systems with a complex vegetation structure can serve as an insurance against insect pest outbreaks and other threats, especially in smallholder plantations (Tscharntke et al., 2011). Integrating smallholder agroforestry systems (e.g. low use of pesticides; moderate to high shade levels; high fruiting tree diversity) into conservation strategies within tropical landscapes has become an even more attractive concept since it has been shown that win-win situations can be realized for both farmers and biodiversity (Perfecto, Vandermeer \& Wright, 2009; Clough et al., 2011; Karp et al., 2013). 
Clearly, the potential of birds and bats to contribute significant economic-service value is great and in need of further quantification. Given the economic impact of these services (Kellermann et al., 2008; Johnson et al., 2010; Boyles et al., 2011, 2013; Karp et al., 2013; Maas et al., 2013), biodiversity-friendly management of tropical farming landscapes provides a promising conservation strategy that may also enhance human well-being through supporting food security and ecosystem resilience (Fischer et al., 2006; Tscharntke et al., 2012a).

\section{CONCLUSIONS}

(1) Insectivorous birds and bats play critical arthropod-limitation roles in both natural and human-dominated ecosystems, with significant constraining effects on arthropod abundances demonstrated in the vast majority of existing studies.

(2) Contrary to ecological theory, the effect of arthropod suppression by birds and bats in the tropics is of similar strength to that in temperate and boreal systems (Van Bael et al., 2003; Van Bael \& Brawn, 2005; Mooney et al., 2010; Mäntylä et al., 2011; Michel, 2012; Morrison \& Lindell, 2012).

(3) While birds and bats characteristically limit arthropods throughout the tropics, the strength of bird- and bat-mediated trophic cascades can be highly variable, depending on insectivore identity, foraging strategies, geographic distributions and resource availability (e.g. primary productivity, arthropod density and diversity, nesting site availability). Additionally, the impact of arthropod suppression depends on factors such as species density, functional diversity (Philpott et al., 2009), and the presence of migratory species (Van Bael et al., 2008; WilliamsGuillén et al., 2008; Michel, 2012). 
(4) In tropical natural systems, speciose bird and bat communities benefit plants through limiting herbivory (e.g. Van Bael et al., 2008). In tropical agricultural systems, insect pest consumption can result in increased yields and substantial economic gains for farmers (Kellermann et al., 2008; Johnson et al., 2010; Boyles et al., 2011, 2013; Karp et al., 2013; Maas et al., 2013).

However, it is unclear how transferable results and recommendations are among different regions and land-use systems, highlighting the need for further research in underrepresented areas.

(5) A number of critical research gaps and unanswered questions remain with respect to steps necessary to safeguard tropical bird and bat communities and the services they provide. Thus, we strongly recommend further studies on the importance of ecosystem services provided by highly functionally diverse and mobile predator groups such as birds and bats with special focus on their economic importance, potential impact on human well-being and biodiversity-friendly land-use management. Such studies will provide real-world implications for improved agricultural management, especially in tropical areas where agricultural expansion and land-use intensification represent serious threats to biodiversity and ecosystem processes.

\section{ACKNOWLEDGEMENTS}

We thank all scientists, field assistants, local communities and research funders supporting ecosystem-service research for their contribution to a better understanding of these complex services and their relationship to human well-being, biodiversity conservation and land-use management. Your hard work and commitment on several field exclosure studies greatly promoted the literature in that field within recent years and not only provides the theoretical background for this review but facilitates real-world implications for land-use management and biodiversity conservation in many areas worldwide. We wish to thank Ed Turner and one 
anonymous reviewer for their valuable suggestions. B.M., K.D. and T.T. were supported by the DFG (CRC 990 EFForTS), P.J.T. and T.T. by the BMBF (SPACES: Limpopo Living Landscapes), P.J.T. by the South African National Research Foundation, Department of Science and Technology, University of Venda and Southern African Macadamia Growers'Association. D.S.K. was supported by a NatureNet Science Fellowship from the Nature Conservancy. J.J.M. was supported by a grant from Bat Conservation International. N.L.M. was supported by Environment Canada and the University of Saskatchewan. L.M. was supported by the Spanish Ministry Of Research And Innovation (MICINN-FEDER: CGL2007-64080-C02-01/BOS, CGL2010-18182). K.W.G. was supported by NSF grant \#DBI-0610473 and Bat Conservation International, as well as by a NSF grant \#DEB-0349388 to I.P. R.M.S. was supported by the State University of Santa Cruz and the Mars Center for Cocoa Science.

\section{REFERENCES}

Barbaro, L., Giffard, B., Charbonnier, Y., van HALder, I. \& Brockerhoff, E. G. (2014). Bird functional diversity enhances insectivory at forest edges: a transcontinental experiment. Diversity and Distributions 20, 149-159.

BARBER, N. A., MARQUIS, R. J. \& TORI, W. P. (2008). Invasive prey impacts regional distribution of native predators. Ecology 89, 2678-2683.

Béchet, A., GirouX, J. F., Gauthier, G., Nichols, J. D. \& Hines, J. E. (2003). Spring hunting changes the regional movements of migrating greater snow geese. Journal of Applied Ecology 40, 553-564.

BÉlisle, M., Desrochers, A. \& Fortin, M. J. (2001). Influence of forest cover on the movements of forest birds: a homing experiment. Ecology 82, 1893-1904. 


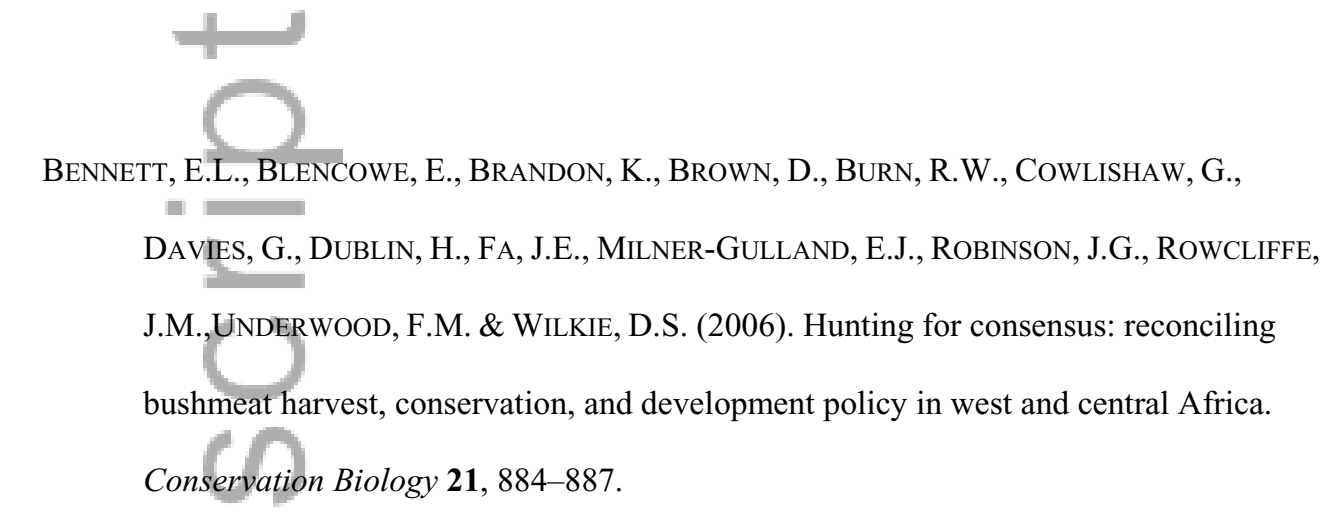

Bhagwat, S. A., Willis, K. J., BiRKs, H. J. B. \& WhitTAKER, R. J. (2008). Agroforestry: a refuge for tropical biodiversity? Trends in Ecology and Evolution 23, 261-267.

BiAnCHI, F. J. J. A., BoOIJ, C. J. H. \& TsCHARNTKE, T. (2006). Sustainable pest regulation in agricultural landscapes: a review on landscape composition, biodiversity natural pest control. Proceedings of the Royal Society B: Biological Sciences 273, 1715-1727.

Boege, K. \& MARQuis, R. J. (2006). Plant quality and predation risk mediated by plant ontogeny: consequences for herbivores and plants. Oikos 115, 559-572.

Bohmann, K., Monadjem, A., Noer, C. L., Rasmussen, M., Zeale, M. R. K., Clare, E., Jones, G., Willerslev, E. \& Gilbert, M. T. P. (2011). Molecular Diet Analysis of Two African Free-Tailed Bats (Molossidae) Using High Throughput Sequencing. PloS One 6.

Borer, E. T., SeABloom, E. W., Shurin, J. B., Anderson, K. E., Blanchette, C. A., Brottman, B., COOPER, S. D. \& HALPERN, B. S. (2005). What determines the strength of a trophic cascade? Ecology 86, 528-537.

Borkhataria, R. R., Collazo, J. A. \& Groom, M. T. (2006). Additive effects of vertebrate predators on insects in a Puerto Rican coffee plantation. Ecological Applications 16, 696703.

Boyles, J. G., Cryan, P. M., McCracken, G. F. \& KunZ, T. H. (2011). Economic importance of bats in agriculture. Science 332, 41-42. 


\section{Boyles, J. G., Sole, C. L., Cryan, P. M., \& McCracken, G. F. (2013). On Estimating the}

Economic Value of Insectivorous Bats: Prospects and Priorities for Biologists. In Bat

Evolution, Ecology, and Conservation, pp. 501-515. Springer New York.

Bregman, T.P., EKERCIO LU, C. H., \& TOBIAS, J. A. (2014). Global patterns and predictors of bird species responses to forest fragmentation: Implications for ecosystem function and conservation. Biological Conservation 169, 372-383.

Brown, V. A. (2010). Molecular analysis of guano from bats in bat houses on organic pecan orchards. MSc thesis. University of Tennessee-Knoxville.

Bumrungsri S., Harbit, A., Benzie, C., Carmouche, K., Sridith, K. \& Racey, P. (2008). The pollination ecology of two species of Parkia (Mimosaceae) in southern Thailand. Journal of Tropical Ecology 24, 467

Bumrungsri, S., Sripaoraya, E., Chongsiri, T., Sridith, K. \& Racey, P. A. (2009). The pollination ecology of durian (Durio zibethinus, Bombacaceae) in southern Thailand. Journal of Tropical Ecology 25, 85

Calcagno, V., Sun, C., Schmitz, O. J. \& Loreau, M. (2011). Keystone Predation and Plant Species Coexistence: The Role of Carnivore Hunting Mode. The American Naturalist 177, E1-E13.

CAMPBELL, C. (1983). The assessment of mealybugs (Pseudococcidae) and other Homoptera on mature cocoa trees in Ghana. Bulletin of Entomological Research 73, 137-151.

Clare, E. L., Barber, B. R., Sweeney, B. W., Hebert, P. D. N. \& Fenton, M. B. (2011) Eating local: Influences of habitat on the diet of little brown bats (Myotis lucifugus). Molecular Ecology 20: 1772-1870.

Classen, A., Peters, M. K., Ferger, S. W., Helbig-Bonitz, M., Schmack, J. M., MaAssen, 
G., Schleuning, M., Kalko, E. K., Böhning-Gaese, K. \& Steffan-Dewenter, I.

(2014). Complementary ecosystem services provided by pest predators and pollinators increase quantity and quality of coffee yields. Proceedings of the Royal Society B:

Biological Sciences 281, 20133148

Cleveland, C. J., Betke, M., Federico, P., Frank, J. D., Hallam, T. G., Horn, J., López Jr., J. D., McCracken, G. F., Medellín, R. A., Moreno-Valdez, A., Sansone, C. G., WestBRoOK, J. K. \& KunZ, T. H. (2006). Economic value of the pest control service provided by Brazilian free-tailed bats in south-central Texas. Frontiers in Ecology and the Environment 4, 238-243.

Clough, Y., Barkmann, J., Juhrbandt, J., Kessler, M., Wanger, T. C., Anshary, A., Buchori, D., Cicuzza, D., Darras, K., Dwi Putra, D. Erasmi, S., Pitopang, R., Schmidt, C., Schulze, C. H., Seidel, D., Steffan-Dewenter, I., Stenchly, K., Vidal, S., Weist M., Wielgoss A. C. \& TscharntKe, T. (2011). Combining high biodiversity with high yields in tropical agroforests. Proceedings of the National Academy of Sciences 108, 8311-8316.

Clough, Y., Dwi Putra, D., Pitopang, R. \& Tscharntke, T. (2009a). Local and landscape factors determine functional bird diversity in Indonesian cacao agroforestry. Biological Conservation 142, 1032-1041.

Clough, Y., FAUST, H. \& TSCHARnTKe, T. (2009b). Cacao boom and bust: sustainability of agroforests and opportunities for biodiversity conservation. Conservation Letters 2, 197 205.

Coley, P. D. \& BARone, J. A. (1996). Herbivory and plant defenses in tropical forests. Annual Review of Ecology, Evolution, and Systematics 27, 305-335. 


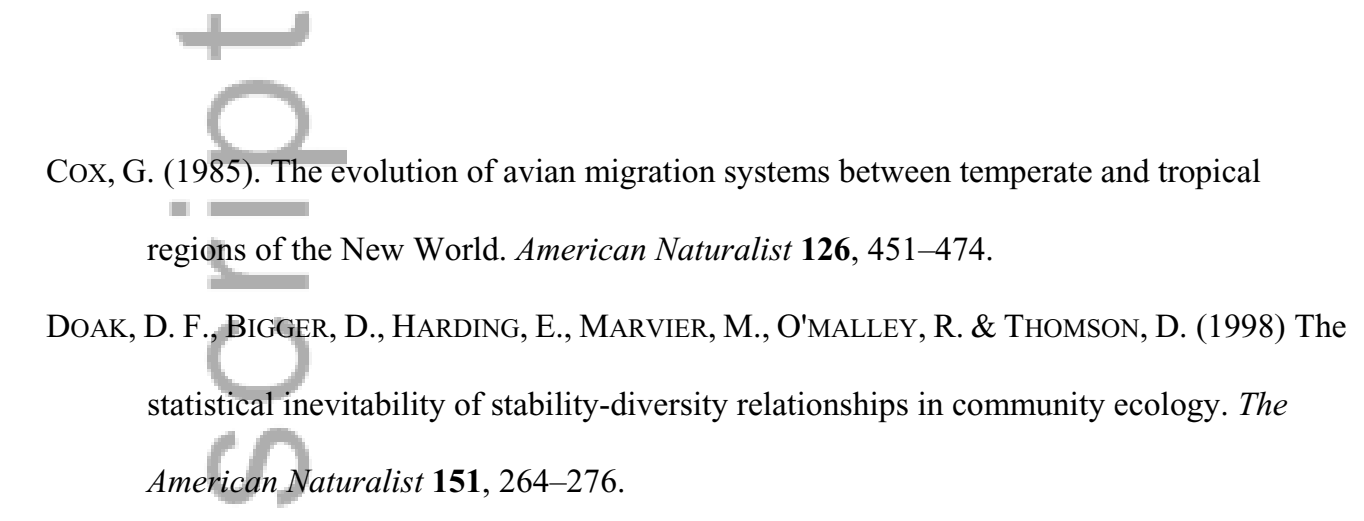

DunHAM, A. E. (2008). Above and below ground impacts of terrestrial mammals and birds in a tropical forest. Oikos 117, 571-579.

Erasmus, B. F., Van JaArsveld, A. S., Chown, S. L., Kshatriya, M. \& Wessels, K. J. (2002). Vulnerability of South African animal taxa to climate change. Global Change Biology $\mathbf{8}$, $679-693$.

ERICKSON, J. L. \& WEST, S. D. (2002). The influence of regional climate and nightly weather conditions on activity patterns of insectivorous bats. Acta Chiropterologica 4, 17-24.

Evans, H. C. (2007). Cacao diseases-the trilogy revisited. Phytopathology 97, 1640-1643.

FARIA, D., LAPS, R. R., BAUMgARTEN, J. \& CETRA, M. (2006). Bat and bird assemblages from forests and shade cacao plantations in two contrasting landscapes in the Atlantic Forest of southern Bahia, Brazil. Biodiversity and Conservation 15, 587-612.

FAYT, P., MACHMER, M. M. \& STEEGER, C. (2005). Regulation of spruce bark beetles by woodpeckers - a literature review. Forest Ecology and Management 206, 1-14.

FINKE, D. L. \& DENNO, R.F. (2005). Predator diversity and the functioning of ecosystems: the role of intraguild predation in dampening trophic cascades. Ecology Letters, 8, 12991306.

Fischer, J., LindenMAYER, D. B. \& MANNING, A. D. (2006). Biodiversity, ecosystem function, and resilience: ten guiding principles for commodity production landscapes. Frontiers in 
Ecology and the Environment 4, 80-86.

Flaquer, C., TORRE, I. \& RUIZ-JARILlo, R. (2006). The value of bat-boxes in the conservation of Pipistrellus pygmaeus in wetland rice paddies. Biological conservation 128, 223-230.

FLEMING, T. H. \& EBy, P. (2005). Ecology of bat migration. In Bat Ecology (ed. H. T. Kunz \& Fenton, M. B. ), pp. 156-208. University of Chicago Press, Chicago, IL, USA.

Flower, C. E., Long, L. C., Knight, K. S., Rebbeck, J., Brown, J. S., GonZAlez-Meler, M. A. \& WHELAN, C. J. (2014). Native bark-foraging birds preferentially forage in infected ash (Fraxinus spp.) and prove effective predators of the invasive emerald ash borer (Agrilus planipennis Fairmaire). Forest Ecology and Management 313, 300-306.

Flynn, D. F. B., Gogol-Prokurat, M., Nogeire, T., Molinari, N., Richers, B. T., Lin, B. B., SimPSON, N., MAYFIELD, M. M. \& DECLERCK, F. (2009). Loss of functional diversity under land use intensification across multiple taxa. Ecology Letters 12, 22-33.

FujitA, M. S. \& TutTLE, M. D. (1991) Flying foxes (Chiroptera: Pteropodidae): threatened animals of key ecological and economic importance. Conservation Biology 5, 455-463.

FUREY, N.M., MACKIE, I.J. \& RACEY, P.A. (2010). Bat diversity in Vietnamese limestone karst areas and the implications of forest degradation. Biodiversity Conservation 19, $1821-$ 1838

Geluso, K. N., AltenBaCh, J. S. \& Wilson, D. E. (1976). Bat mortality: pesticide poisoning and migratory stress. Science 194, 184-186.

GREENBERG, R. (1995). Insectivorous migratory birds in tropical ecosystems: the breeding currency hypothesis. Journal of Avian Biology 26, 260-264. 


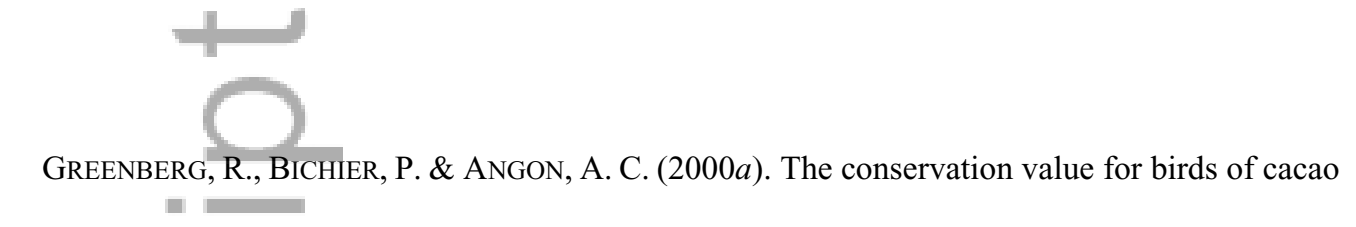
plantations with diverse planted shade in Tabasco, Mexico. Animal Conservation 3, 105112.

Greenberg, R., Bichier, P., Angon, A. C., MacVean, C., Perez, R. \& Cano, E. (2000b). The impact of avian insectivory on arthropods and leaf damage in some guatemalan coffee plantations. Ecology 81, 1750-1755.

GreEnBerg, R., BiCHIER, P. \& Sterling, J. (1997a). Acacia, cattle and migratory birds in southeastern Mexico. Biological Conservation 80, 235-247

Greenberg, R., Bichier, P. \& Sterling, J. (1997b). Bird populations in rustic and planted shade coffee plantations of eastern Chiapas, Mexico. Biotropica, 29, 501-514.

GREENBERG, R. \& ORTIZ, J. S. (1994). Interspecific defense of pasture trees by wintering yellow warblers. The Auk 111, 672-682.

GRUNER, D. S. (2004). Attenuation of top-down and bottom-up forces in a complex terrestrial community. Ecology 85, 3010-3022.

GRUNER, D. S. (2005). Biotic resistance to an invasive spider conferred by generalist insectivorous birds on Hawai'i Island. Biological Invasions 7, 541-546.

GRUNER, D. S. \& TAYLOR, A.D. (2006). Richness and species composition of arboreal arthropods affected by nutrients and predators: A press experiment. Oecologia 147, 714-724.

GunNarsson, B. (2007). Predation on spiders: Ecological mechanisms and evolutionary consequences. Journal of Arachnology 35, 509-529.

HALAJ, J. \& D. H. WiSE. (2001). Terrestrial trophic cascades: how much do they trickle? The American Naturalist 157, 262-281. 


\section{$+$ \\ Hallmann, C. A., Foppen, R. P., van Turnhout, C. A., DE Kroon, H. \& Jongejans, E. (2014).}

Declines in insectivorous birds are associated with high neonicotinoid concentrations.

Nature. doi:10.1038/nature13531

Hansen, A. J., Neilson, R. P., Dale, V. H., Flather, C. H., Iverson, L. R., Currie, D. J., SHAFER, S., COOK, R. \& BARTLEIN, P. J. (2001). Global Change in Forests: Responses of Species, Communities, and Biomes Interactions between climate change and land use are projected to cause large shifts in biodiversity. BioScience 51, 765-779.

Harvey, C.A., Medina, A., Sanchez, D. M., Vilchez, S., Hernandez, B., Saenz, J. C., Maes, J. M., CASANOVES, F. \& SinClaIR, F. L. (2006). Patterns of animal diversity in different forms of tree cover in agricultural landscapes. Ecological Applications 16, 1986-1999.

HaRVEY, C. A. \& Villalobos, J. A. G. (2007). Agroforestry systems conserve species-rich but modified assemblages of tropical birds and bats. Biodiversity and Conservation 16, $2257-$ 2292.

HOOKS, C. R. R., PANDEY, R. R. \& JOHNSON, M. W. (2003). Impact of avian and arthropod predation of Lepidopteran caterpillar densities and plant productivity in an ephemeral agroecosystem. Ecological Entomology 28, 522-532.

HoOKs, C. R. R., PANDEY, R. R. \& JOHNSON, M. W. (2006). Effects of spider presence on Artogeia rapae and host plant biomass. Agriculture, Ecosystems \& Environment 112, 7377.

Huston, M. A. (1997). Hidden treatments in ecological experiments: re-evaluating the ecosystem function of biodiversity. Oecologia, 110, 449-460.

IUCN SPECIES SuRvival Commission. (2004). IUCN Red List of Threatened Species: A Global Species Assessment. 
JANZEN, D. H. \& SCHOENER, T. W. (1968). Differences in insect abundance and diversity between 플 wetter and drier sites during a tropical dry season. Ecology 49, 96-110.

JIRINEC, V., CAMPOS, B. R. \& JOHNSON, M. D. (2011). Roosting behaviour of a migratory songbird on Jamaican coffee farms: landscape composition may affect delivery of an ecosystem service. Bird Conservation International 21, 353-361.

Johnson, M. D., Kellermann, J. L. \& Stercho, A. M. (2010). Pest reduction services by birds in shade and sun coffee in Jamaica. Animal Conservation 13, 140-147.

Johnson, M. D., Levy, N. J., Kellermann, J. L. \& Robinson, D. E. (2009). Effects of shade and bird exclusion on arthropods and leaf damage on coffee farms in Jamaica's Blue Mountains. Agroforestry Systems 76, 139-148.

Kagata, H. \& OHgushi, T. (2006). Bottom-up trophic cascades and material transfer in terrestrial food webs. Ecological Research 21, 26-34.

KALKA, M. \& KALKO, E. K. V. (2006). Gleaning bats as underestimated predators of herbivorous insects: diet of Micronycteris microtis (Phyllostomidae) in Panama. Journal of Tropical Ecology 22, 1-10.

Kalka, M. B., SMith, A. R. \& Kalko, E. K. V. (2008). Bats limit arthropods and herbivory in a tropical forest. Science 320, 71-71.

KARP, D. S. \& DAILY, G. C. (2014). Cascading effects of insectivorous birds and bats in tropical coffee plantations. Ecology 95, 1065-1074.

Karp, D. S., Mendenhall, C. D., Sandí, R. F., Chaumont, N., Ehrlich, P. R., Hadly, E. A. \& DAILY, G. C. (2013). Forest bolsters bird abundance, pest control and coffee yield. Ecology Letters 16, 1339-1347. 
KARP, D. S., ZIV, G., ZoOK, J., EhrLICH, P. R. \& DAILY, G. C. (2011). Resilience and stability in bird guilds across tropical countryside. Proceedings of the National Academy of Sciences 108, 21134-21139.

Kéfi, S., Berlow, E. L., Wieters, E. A., Navarrete, S. A., Petchey, O. L., Wood, S. A., Boit, A., Joppa, L. N., Lafferty, K. D., Williams, R. J., Martinez, N. D., Menge, B. A., Blanchette, C. A., Iles, A. C. \& Brose, U. (2012). More than a meal... integrating nonfeeding interactions into food webs. Ecology Letters 15, 291-300.

Kellermann, J. L., Johnson, M. D., Stercho, A. M. \& Hackett, S. C. (2008). Ecological and economic services provided by birds on Jamaican Blue Mountain coffee farms.

Conservation Biology 22, 1177-1185.

KELM, D. H., WIESNER, K. R. \& VON HELVERSEN, O. (2008). Effects of Artificial Roosts for Frugivorous Bats on Seed Dispersal in a Neotropical Forest Pasture Mosaic.

Conservation Biology 22, 1370-1370.

KInGSTON, T. (2013). Response of bat diversity to forest disturbance in Southeast Asia: insights from long-Term research in Malaysia, in: Adams, R.A., Pedersen, S.C. (Eds.), Bat Evolution, Ecology, and Conservation. Springer New York, New York, pp. 169-185. KISER, M. (2002). North American Bat House Research Project: BCI's volunteer researchers design better homes for bats. BATS Magazine 20, 19-21.

KissLing, W. D., EKERCIO LU, C. H. \& JETZ, W. (2012). Bird dietary guild richness across latitudes, environments and biogeographic regions. Global Ecology and Biogeography 3, $328-340$. 
Koenig, W. D., LiebHold, A. M., Bonter, D. N., HochachKa, W. M., Dickinson, J. L. (2013).

Effects of the emerald ash borer invasion on four species of birds. Biological Invasions

15, 2905-2913.

KoH, L. P. (2010). Birds defend oil palms from herbivorous insects. Ecological Applications 18, $821-825$.

KunZ, T. H., ANTHONY, E. L. \& RuMAGE III, W. T. (1977). Mortality of little brown bats following multiple pesticide applications. The Journal of Wildlife Management 476-483.

Kunz, T. H., Braun de Torrez, E., Bauer, D., Lobova, T. \& Fleming, T. H. (2011). Ecosystem services provided by bats. In Year in Ecology and Conservation Biology, 1223. Annals of the New York Academy of Sciences (eds R. S. Ostfeld \& W. H. Schlesinger), pp. 1-38.

KunZ, T. H. \& LUMSDEN, L. F. (2005). Ecology of Cavity and Foliage Roosting bats. In Bat Ecology (eds T. H. Kunz and M. B. Fenton), pp. 3-89. University of Chicago Press, Chicago, IL, USA.

KunZ, T. H., WhitAKer JR, J. O., \& WADANOLI, M. D. (1995). Dietary energetics of the insectivorous Mexican free-tailed bat (Tadarida brasiliensis) during pregnancy and lactation. Oecologia 101, 407-415.

LAurance, W. F., SAYer, J. \& CASSMan, K. G. (2014). Agricultural expansion and its impacts on tropical nature. Trends in Ecology \& Evolution 29, 107-116.

Leibold, M. A., Holyoak, M., Mouquet, N., Amarasekare, P., Chase, J. M., Hoopes, F., Holt, R. D., Shurin, J. B., Law, R., Tilman, D., Loreau, M. \& Gonzalez, A. (2004). The metacommunity concept: a framework for multi-scale community ecology. Ecology Letters 7, 601-613. 


\section{LetourneaU, D. K., JedLicka, J. A., Bothwell, S. G. \& Moreno, C. R. (2009). Effects of}

natural enemy biodiversity on the suppression of arthropod herbivores in terrestrial ecosystems. Annual Review of Ecology, Evolution, and Systematics 40, 573-592.

LEYEQUIEN, E., DE BoER, W. F. \& TOLEDO, V. M. (2010). Bird community composition in a shaded coffee agro-ecological matrix in Puebla, Mexico: the effects of landscape heterogeneity at multiple spatial scales. Biotropica 42, 236-245.

LOEB, S. C. \& O'KeEFE, J. M. (2006). Habitat use by forest bats in South Carolina in relation to local, stand, and landscape characteristics. Journal of Wildife Management 70, 12101218.

LOYN, R. H., RUNNALLS, R. G. \& FORWARD, G. Y. (1983). Territorial bell miners and other birds affecting populations of insect prey. Science 221, 1411-1413.

LUNDBERG, J. \& MoBERG, F. (2003). Mobile link organisms and ecosystem functioning: Implications for ecosystem resilience and management. Ecosystems 6, 87-98.

MAAS, B., ClOUGH, Y. \& TSCHARnTKE, T. (2013). Bats and birds increase crop yield in tropical agroforestry landscapes. Ecology Letters 16, 1480-1487.

MaAs, B., Putra, D. D., Waltert, M., Clough, Y., TscharntKe, T., \& Schulze, C. H. (2009). Six years of habitat modification in a tropical rainforest margin of Indonesia do not affect bird diversity but endemic forest species. Biological Conservation 142, 2665-2671.

MaAs, B., TscharntKe, T., SAleh, S., Dwi-Putra, D. \& Clough, Y. (2015). Avian species identity drives predation success in tropical cacao agroforestry. Journal of Applied Ecology. Doi: 10.1111/1365-2664.12409

MacSwiney, G., Cristina, M., Clarke, F. M., \& Racey, P. A. (2008). What you see is not what you get: the role of ultrasonic detectors in increasing inventory completeness in 
Neotropical bat assemblages. Journal of Applied Ecology 45, 1364-1371.

MÄNTYLÄ, E., Klemola, T. \& LAAKSOnEN, T. (2011). Birds help plants: A meta-analysis of topdown trophic cascades caused by avian predators. Oecologia 165, 143-151.

MARQUIS, R. \& WHELAN, C. (1994). Insectivorous birds increase growth of white oak through consumption of leaf-chewing insects. Ecology 75, 2007-2014.

Marsden, S. J., SYMES, C. T. \& MACK, A. L. (2006). The response of a New Guinean avifauna to conversion of forest to small-scale agriculture. Ibis 148, 629-640

Martin, E. A., Reineking, B., Seo, B., \& Steffan-Dewenter, I. (2013). Natural enemy interactions constrain pest control in complex agricultural landscapes. Proceedings of the National Academy of Sciences of the United States of America 110, 5534-5539.

McCracken, G. F., Westbrook, J. K., Brown, V. A., Eldridge, M., Federico, P. \& Kunz, T.

H. (2012). Bats track and exploit changes in insect pest populations. PLoS One 7.

McShane, T. O., Hirsch, P. D., Trung, T. C., Songorwa, A. N., Kinzig, A., Monteferri, B., Mutekanga, D., Van Thang, H., Dammert, J. L., Pulgar-Vidal, M., Welch-Devine, M., Brosius, J. P., Coppolillo, P. \& O’ConNor, S. (2011). Hard choices: Making tradeoffs between biodiversity conservation and human well-being. Biological Conservation 144, 966-972.

Mendenhall, C. D., Karp, D. S., Meyer, C. F. J., Hadly, E. A. \& Daily, G. C. (2014)

Predicting biodiversity change and averting collapse in agricultural landscapes. Nature $509,213-217$.

Melo, F. P., Arroyo-Rodríguez, V., FAhrig, L., Martínez-RAmos, M. \& TABARElli, M. (2013). On the hope for biodiversity-friendly tropical landscapes. Trends in Ecology \& Evolution 28, 462-468. 
Mestre, L., GARCIA, N., BArrientos, J. A., EsPADALER, X. \& PiÑol, J. (2013). Bird predation affects diurnal and nocturnal web-building spiders in a Mediterranean citrus grove. Acta aecologica 4 . Oecologica 47, 74-80.

Mestre, L., Piñol, J., Barrientos, J. A., CAMA, A., \& EsPadaler, X. (2012). Effects of ant competition and bird predation on the spider assemblage of a citrus grove. Basic and Applied Ecology 13, 355-362.

MiCHEL, N. L. (2012). Mechanisms and consequences of avian understory insectivore population decline in fragmented Neotropical rainforest. PhD thesis, Tulane University, New Orleans, LA.

MiCHEL, N. L., SHERRY, T. W. \& CARSON, W. P. (2014). The omnivorous collared peccary negates an insectivore-generated trophic cascade in Costa Rican wet tropical forest understorey. Journal of Tropical Ecology 30, 1-11.

MillenNium ECOSYstem Assessment (2005). Ecosystems and human well-being: Synthesis. Island Press, Washington, DC.

Moguel, P. \& Toledo, V. M. (1999). Biodiversity conservation in traditional coffee systems of Mexico. Conservation Biology 13, 11-21.

Mooney, K. A., Gruner, D. S., Barber, N. A., Van Bael, S. A., Philpott, S. M. \& GREENBERG, R. (2010). Interactions among predators and the cascading effects of vertebrate insectivores on arthropod communities and plants. Proceedings of the National Academy of Sciences 107, 7335-7340.

MoOnEy, K. A. \& LinharT, Y.B. (2006). Contrasting cascades: insectivorous birds increase pine but not parasitic mistletoe growth. Journal of Animal Ecology 75, 350-357. 
Moore, R. P., Robinson, W. D., Lovette, I. J. \& Robinson, T. R. (2008). Experimental evidence for extreme dispersal limitation in tropical forest birds. Ecology Letters, 11, $960-968$.

Morrison, E. B. \& Lindell, C. A. (2012). Birds and bats reduce insect biomass and leaf damage in tropical forest restoration sites. Ecological Applications 22, 1526-1534.

MunN, C. A. \& TERBORGH, J. W. (1979). Multi-species territoriality in neotropical foraging flocks. Condor 81, 338-347.

Muscarella, R. \& Fleming, T. H. (2007). The role of frugivorous bats in tropical forest succession. Biological Reviews 82, 573-590.

NEWMARK, W. D. (2006). A 16-year study of forest disturbance and understory bird community structure and composition in Tanzania. Conservation Biology 20, 122-134.

NiJMAN, V. (2010). An overview of international wildlife trade from Southeast Asia. Biodiversity and conservation, 19, 1101-1114.

Olson, D. M., Dinerstein, E., Wikramanayake, E. D., Burgess, N. D., Powell, G. V., Underwood, E. C., D'Amico, J. A., Itoua, I., Strand, H. E., Morrison, J. C., Loucks, C. J., Allnutt, T. F., Ricketts, T. H., Kura, Y., LAmoreuX, J. F., Wettengel, W. W., HEDAO, P. \& KASSEM, K. R. (2001). Terrestrial Ecoregions of the World: A New Map of Life on Earth A new global map of terrestrial ecoregions provides an innovative tool for conserving biodiversity. BioScience 51, 933-938.

Patterson, B. D., PAcheco, V. \& Solari, S. (1996). Distribution of bats along an elevational gradient in the Andes of south-eastern Peru. Journal of Zoology, 240, 637-658.

Patterson, B. D., Willig, M. R. \& Stevens, R. D. (2005). Trophic startegies, niche partitioning, and patterns of ecological organization. In Bat Ecology (eds H. T. Kunz and 
M. B. Fenton), pp. 536-579. The University of Chicago Press, Chicago, IL, USA.

Peh, K. S. H., Sodhi, N. S., DE Jong, J., EKercio LU, C. H., YAP, C. A. M. \& LiM, S. L. H. (2006). Conservation value of degraded habitats for forest birds in southern Peninsular Malaysia. Diversity \& Distributions 12, 572-581

Perfecto, I., Rice, R. A., Greenberg, R. \& VAn der Voort, M. E. (1996). Shade coffee: a disappearing refuge for biodiversity. BioScience, 598-608.

Perfecto, I., VAndermeer, J. H., Bautista, G. L., Nunez, G. I., Greenberg, R., Bichier, P. \& LANGRIDGE, S. (2004). Greater predation in shaded coffee farms: The role of resident neotropical birds. Ecology 85, 2677-2681.

Perfecto, I., VANDERMEeR, J. H. \& Wright, A. L. (2009). Nature's matrix: linking agriculture, conservation and food sovereignty. Earthscan.

Philpott, S. M., Arendt, W. J., Armbrecht, I., Bichier, P., Diestch, T. V., Gordon, C., Greenberg, R., Perfecto, I., Reynoso-Santos, R., Soto-Pinto, L., Tejeda-Cruz, C., Williams-Linera, G., VAlenZuela, J. \& ZolotofF, J. M. (2008). Biodiversity loss in Latin American coffee landscapes: Review of the evidence on ants, birds, and trees.

Conservation Biology 22, 1093-1105.

Philpott, S. M., GreEnBERG, R. \& Bichier, P. (2005). The influence of ants on the foraging behavior of birds in an agroforest. Biotropica 37, 468-471.

Philpott, S. M., Greenberg, R., Bichier, P. \& Perfecto, I. (2004). Impacts of major predators on tropical agroforest arthropods: comparisons within and across taxa. Oecologia 140, $140-149$. 


\section{PhilPotT, S. M., SOONG, O., LowENSTEIN, J. H., PULIDO, A. L., LOPEZ, D. T., FLYNN, D. F. \&}

DECleRCK, F. (2009). Functional richness and ecosystem services: bird predation on arthropods in tropical agroecosystems. Ecological Applications 19, 1858-1867.

Phommexay, P., Satasook, C., Bates, P., Pearch, M. \& Bumrungsri, S. (2011). The impact of rubber plantations on the diversity and activity of understorey insectivorous bats in southern Thailand. Biodiversity Conservation 20, 1441-1456.

Polis, G. A., ANDERSON, W. B. \& Holt, R. D. (1997). Toward an integration of landscape and food web ecology: The dynamics of spatially subsidized food webs. Annual Review of Ecology and Systematics 28, 289-316.

PoLIS, G. A. \& HoLT, R. D. (1992). Intraguild predation: The dynamics of complex trophic interactions. Trends in Ecology \& Evolution 3, 151-154.

Polis, G. A. \& STRONG D. R. (1996). Food web complexity and community dynamics. The American Naturalist 147, 813-846.

RAILSBACK, S. F. \& JOHNSON, M. D. (2014). Effects of land use on bird populations and pest control services on coffee farms. Proceedings of the National Academy of Sciences of the United States of America 111, 6109-6114.

Rice, R. A., \& GREENBERG, R. (2000). Cacao cultivation and the conservation of biological diversity. AMBIO: A Journal of the Human Environment 29, 167-173.

RichteR, H.V. \& CUMming, G. S. (2008). First application of satellite telemetry to track African straw-coloured fruit bat migration. Journal of Zoology 275, 172-176.

RUiZ-GuerRA, B., RENTON, K. \& Dirzo, R. (2012). Consequences of fragmentation of tropical moist forest for birds and their role in predation of herbivorous insects. Biotropica $\mathbf{4 4}$, 228-236. 
SCHEFFERS, B. R., CORLETT, R. T., DieSMOS, A., \& LAURANCE, W. F. (2012). Local demand drives a bushmeat industry in a Philippine forest preserve. Tropical Conservation Science, 5, 133-141.

SchmitZ, O. J. (2007). Predator diversity and trophic interactions. Ecology 88, 2415-2426.

SCHMitZ, O. J., HAMBÄCK, P. A. \& BeCKeRMAN, A. P. (2000). Trophic cascades in terrestrial systems: a review of the effects of carnivore removals on plants. The American Naturalist 155, 141-153.

EKERCIO LU, C. H. (2006a). Ecological significance of bird populations. In Handbook of the

Birds of the World, vol. 11. (eds. J. del Hoyo, J., A. Elliott and D. A. Christie), pp. 15-51.

Lynx Press and BirdLife International. Barcelona and Cambridge.

EKERCIO LU, C. H. (2006b). Increasing awareness of avian ecological function. Trends in Ecology \& Evolution 21, 464-471.

EKERCIO LU, C. H. (2012). Bird functional diversity in tropical forests, agroforests and open agricultural areas. Journal of Ornithology 153, 153-161.

${ }^{\wedge}$ EKERCIO LU, Ç. H., DAILY, G. C. \& EHRLICH, P. R. (2004). Ecosystem consequences of bird declines. Proceedings of the National Academy of Sciences, 101, 18042-18047.

$\wedge^{\wedge}$ ekercio lu, Ç. H., Ehrlich, P. R., Daily, G. C., Aygen, D., Goehring, D. \& SANDi, R. F. (2002). Disappearance of insectivorous birds from tropical forest fragments. Proceedings of the National Academy of Sciences of the United States of America 99, 263-267. EKercio LU, C. H., LOARIE, S. R., Oviedo Brenes, F., Ehrlich, P. R., \& DAily, G. C. (2007). Persistence of forest birds in the Costa Rican agricultural countryside. Conservation Biology, 21(2), 482-494.

${ }^{\wedge}$ EKERCIO LU, Ç. H., WENNY, D. \& WHELAN, C.J. (Eds.). In press. Why Birds Matter. University 
of Chicago Press. Chicago

Senthilkumar, K., Kannan, K., Subramanian, A. \& Tanabe, S. (2001). Accumulation of organochlorine pesticides and polychlorinated biphenyls in sediments, aquatic organisms, birds, bird eggs and bat collected from south India. Environmental Science and Pollution Research 8, 35-47.

SHERRY, T. W. (1984). Comparative dietary ecology of sympatric, insectivorous Neotropical flycatchers (Tyrannidae). Ecological Monographs 54, 313-338.

Sigel, B. J., Robinson, W. D. \& Sherry, T. W. (2010). Comparing bird community responses to forest fragmentation in two lowland Central American reserves. Biological Conservation $143,340-350$.

Singer, M. S., FArKas, T. E., Skorik, C. M. \& MoOney, K. A. (2012). Tritrophic Interactions at a Community Level alitEffradBsirdf PfodaRbanoSpecies Qu Caterpillars. The American Naturalist 179, 363-374.

SRIthongChUAY, T., BUMrUngSRI, S. \& SRIPAO-RAYA, E. (2008). The pollination ecology of the late-successional tree, Oroxylum indicum (Bignoniaceae) in Thailand. Journal of Tropical Ecology 24, 477.

STRONG, D. R. (1992). Are trophic cascades all wet? Differentiation and donor-control in speciose ecosystems. Ecology 73, 747-754.

Struebig, M. J., Kingston, T., Zubaid, A., Le Comber, S. C., Mohd-Adnan, A., Turner, A., Kelly, J., BozeK, M. \& Rossiter, S. J. (2009). Conservation importance of limestone karst outcrops for Palaeotropical bats in a fragmented landscape. Biological Conservation 142, 2089-2096.

Struebig, M. J., Kingston, T., Zubaid, A., Mohd-Adnan, A. \& Rossiter, S. J. (2008). 
Conservation value of forest fragments to Palaeotropical bats. Biological Conservation

141, 2112-2126.

Struebig, M. J., Turner, A., Giles, E., Lasmana, F., Tollington, S., Bernard, H. \& Bell, D. (2013). Quantifying the biodiversity value of repeatedly logged rainforests: gradient and comparative approaches from Borneo. Advances in Ecological Research, 48, 183-224.

Symondson, W. O. C., Sunderland, K. D., \& Greenstone, M. H. (2002). Can generalist predators be effective biocontrol agents? Annual Review of Entomology 47, 561-594.

Taylor, P. J., Bohmann, K. Steyn, J. N., Schoeman, M. C., Matamba, E., ZePedA-Mendoza, M., NANGAMMBI, T. \& GiLBERT, M. T. P. (2013a). Bats eat pest green vegetable stinkbugs (Nezara viridula): diet analyses of seven insectivorous species of bats roosting and foraging in macadamia orchards at Levubu, Limpopo Province, South Africa. Southern African Macadamia Growers Association Yearbook 21, 37-43.

TAYlor, P. J., Monadjem, A. \& Steyn, J. N. (2013b). Seasonal patterns of habitat use by insectivorous bats in a subtropical African agro-ecosystem dominated by macadamia orchards. African Journal of Ecology 51, 552-561.

TEJADA-CruZ, C. \& Sutherland, W. J. (2004). Bird responses to shade coffee production. Animal Conservation 7, 169-2004.

TSCHARNTKE, T. (1997). Vertebrate effects on plant-invertebrate food webs. In Multitrophic interactions in terrestrial systems (eds A. C. Gange and V. K. Brown), pp. 277-297.

Blackwell Science Ltd. (36th Symposium of The British Ecological Society).

Tscharntke, T., Clough, Y., Bhagwat, S. A., Buchori, D., Faust, H., Hertel, D., Hölscher, D., Juhrbandt, J., Kessler, M., Perfecto, I., Scherber, C., Schroth, G., 
VELDKAMP, E. \& WANGER, T. C. (2011). Multifunctional shade-tree management in tropical groforestry landscapes-a review. Journal of Applied Ecology 48, 619-629.

Tscharntke, T., Clough, Y., Wanger, T. C., Jackson, L., Motzke, I., Perfecto, I.,

VANDERMEER, J. \& WHITBREAD, A. (2012a). Global food security, biodiversity

conservation and the future of agricultural intensification. Biological Conservation 151,

$53-59$

Tscharntke, T., Klein, A. M., Kruess, A., Steffan-Dewenter, I. \& Thies, C. (2005).

Landscape perspectives on agricultural intensification and biodiversity-ecosystem service management. Ecology Letters 8, 857-874.

TscharntKe, T., EKercio lu, C. H., Dietsch, T. V., Sodhi, N. S., Hoehn, P. \& Tylianakis, J. M. (2008). Landscape constraints on functional diversity of birds and insects in tropical agroecosystems. Ecology 89, 944-951.

Tscharntke T., Tylianakis J. M., Rand T. A., Didham R. K., FAhrig L., Batáry P.,

Bengtsson J., Clough Y., Crist T. O., Dormann C. F., Ewers R. W., Fründ J., Holt

R. D., Holzschuh A., Klein A. M., Kleijn D., Kremen C., Landis D. A., Laurance W., LindenMayer D., Scherber C., Sodhi N., StefFan-Dewenter I., Thies C., VAN DER

PUTTEN W. H. \& WeStPHAL, C. (2012b). Landscape moderation of biodiversity patterns and processes - eight hypotheses. Biological Reviews 87, 661-685.

TUTTLE, M. D., KISER, M. \& KISER, S. (2005). The bat house builder's handbook. University of Texas Press, Austin.

URban, M. C., ZARnetske, P. L. \& Skelly, D. K. (2013). Moving forward: dispersal and species interactions determine biotic responses to climate change. Annals of the New York Academy of Sciences 1297, 44-60. 
Van Bael, S. A., Aiello, A., Valderrama, A., Medianero, E., Samaniego, M. \& Wright, S.

J. (2004). General herbivore outbreak following an E1 Niño-related drought in a lowland

Panamanian forest. Journal of Tropical Ecology 20, 625-633.

VAn BAEL, S. A., Bichier, P., \& GREEnBERG, R. (2007a). Bird predation on insects reduces

damage to the foliage of cocoa trees (Theobroma cacao) in western Panama. Journal of

Tropical Ecology 23, 715-719.

VAn BAel, S. A., Bichier, P., OCHOA, I. \& GREEnBERG, R. (2007b). Bird diversity in cacao farms and forest fragments of western Panama. Biodiversity and Conservation 16, 22452256.

VAN BAEL, S. A. \& BRAWN, J. D. (2005). The direct and indirect effects of insectivory by birds in two contrasting Neotropical forests. Oecologia 145, 658-668.

VAN BAEL, S. A., Brawn, J. D. \& RoBInsON, S. K. (2003). Birds defend trees from herbivores in a Neotropical forest canopy. Proceedings of the Royal Society U.S.A. 100, 8304-8307

Van Bael, S. A. V., Philpott, S. M., Greenberg, R., Bichier, P., Barber, N. A., Mooney, K. A., \& GRUNER, D. S. (2008). Birds as predators in tropical agroforestry systems. Ecology 89, 928-934.

VAnce-Chalcraft, H. D., Rosenheim, J. A., Vonesh, J. R., OsenberG, C. W. \& Sih, A. (2007). The influence of intraguild predation on prey suppression and prey release: A metaanalysis. Ecology 88, 2689-2696.

Waltert, M., Bobo, K. S., Sainge, N. M., Fermon, H. \& Muhlenberg, M. (2005). From forest to farmland: habitat effects on Afrotropical forest bird diversity. Ecological Applications 15, 1351-1366.

Wanger, T. C., Darras, K., Bumrungsri, S., TscharntKe, T. \& Klein, A. M. (2014). Bat pest 
control contributes to food security in Thailand. Biological Conservation 171, 220-223.

WERnER, E. E. \& PEACOR, S. D. (2003). A review of trait-mediated indirect interactions in ecological communities. Ecology, 84, 1083-1100.

Whelan, C.J., Brown, J.S., Schmidt, K.A., Steele, B.B. \& Willson, M.F. (2000). Linking consumer-resource theory with digestive physiology: application to diet shifts.

Evolutionary Ecology Research 2, 911-934.

Whelan, C. J., WENNY, D. G. \& MARQuis, R. J. (2008). Ecosystem services provided by birds. In Year in Ecology and Conservation Biology, vol. 1134. (eds R. S. Ostfeld and W. H. Schlesinger), pp. 25-60. Annals of the New York Academy of Sciences.

Whitaker, J. O. JR., MCCracken, G. F. \& Siemers, B. M. (2009). Food habits analysis of insectivorous bats. In Ecological and behavioral methods for the study of bats, vol. 2. (eds T. H. Kunz and S. Parson), pp. 567-592. The John Hopkins University Press, Baltimore.

Wielgoss, A., Clough, Y., Fiala, B., Rumede, A. \& Tscharntke, T. (2012). A minor pest reduces yield losses by a major pest: plant-mediated herbivore interactions in Indonesian cacao. Journal of Applied Ecology 49, 465-473.

Wielgoss, A., TscharntKe, T., Rumede, A., Fiala, B., Seidel, H., Shahabuddin, S. \& Clough, Y. (2014). Interaction complexity matters: disentangling services and disservices of ant communities driving yield in tropical agroecosystems. Proceedings of the Royal Society B: Biological Sciences 281, 20132144.

Wiles, G. J., Brooke, A. P., Fleming, T. H., \& RACEY, P. A. (2010). Conservation threats to bats in the tropical Pacific islands and insular Southeast Asia. Island Bats: Evolution, Ecology, and Conservation. University of Chicago Press, Chicago, 405-459. 


\section{WiLLIAMS-GUILLÉN, K. \& PERFECTO, I. (2010). Effects of Agricultural Intensification on the}

Assemblage of Leaf-Nosed Bats (Phyllostomidae) in a Coffee Landscape in Chiapas, Mexico. Biotropica 42, 605-613.

Williams-Guillén, K. \& Perfecto, I. (2011). Ensemble Composition and Activity Levels of Insectivorous Bats in Response to Management Intensification in Coffee Agroforestry Systems. Plos One 6.

Williams-Guillén, K., Perfecto, I. \& VAndermeer, J. (2008). Bats limit insects in a neotropical agroforestry system. Science 320, 70-70.

YACHI, S., \& LOREAU, M. (1999). Biodiversity and ecosystem productivity in a fluctuating environment: the insurance hypothesis. Proceedings of the National Academy of Sciences 96, 1463-1468.

Yong, D. L., QIE, L., Sodhi, N. S., KoH, L. P., PeH, K. S.-H., LeE, T. M., Lim, H. C. \& LIM, S. L.H. (2011). Do insectivorous bird communities decline on land-bridge forest islands in Peninsular Malaysia? Journal of Tropical Ecology 27, 1-14.

\section{SUPPORTING INFORMATION}

Additional supporting information may be found in the online version of this article.

Table S1. List of reports using exclosure studies of birds and bats to quantify predation effects on arthropod abundances (control versus exclosure treatments) used for the calculation of effectsize graphs in Fig. 3. 
Table 1. Total and endemic species richness of birds and bats living only in one region, for each biogeographic realm (following Olson et al., 2001). Bird data from ekercio lu et al. (2004) and ekercio lu (2012), updated with new ornithological data published until 2014. Bat data from IUCN Red List mammal data (IUCN, 2014).

\begin{tabular}{ccccc} 
Biogeographic & Total bat & Endemic bat & Total bird & Endemic bird \\
species & species & species & species \\
richness & richness & richness & richness \\
\hline Afrotropics & 237 & $211(89 \%)$ & 2,079 & $1,671(80 \%)$ \\
Australasia & 270 & $185(68 \%)$ & 1,399 & $1,019(73 \%)$ \\
Indomalaya & 282 & $124(44 \%)$ & 1,982 & $1,242(63 \%)$ \\
Neotropics & 337 & $255(75 \%)$ & 3,996 & $3,564(89 \%)$ \\
Nearctic & 94 & $12(13 \%)$ & 689 & $173(25 \%)$ \\
Oceania & 14 & $10(71 \%)$ & 375 & $261(70 \%)$ \\
Palearctic & 155 & $41(26 \%)$ & 1,160 & $349(30 \%)$ \\
\hline
\end{tabular}




\section{Figures}

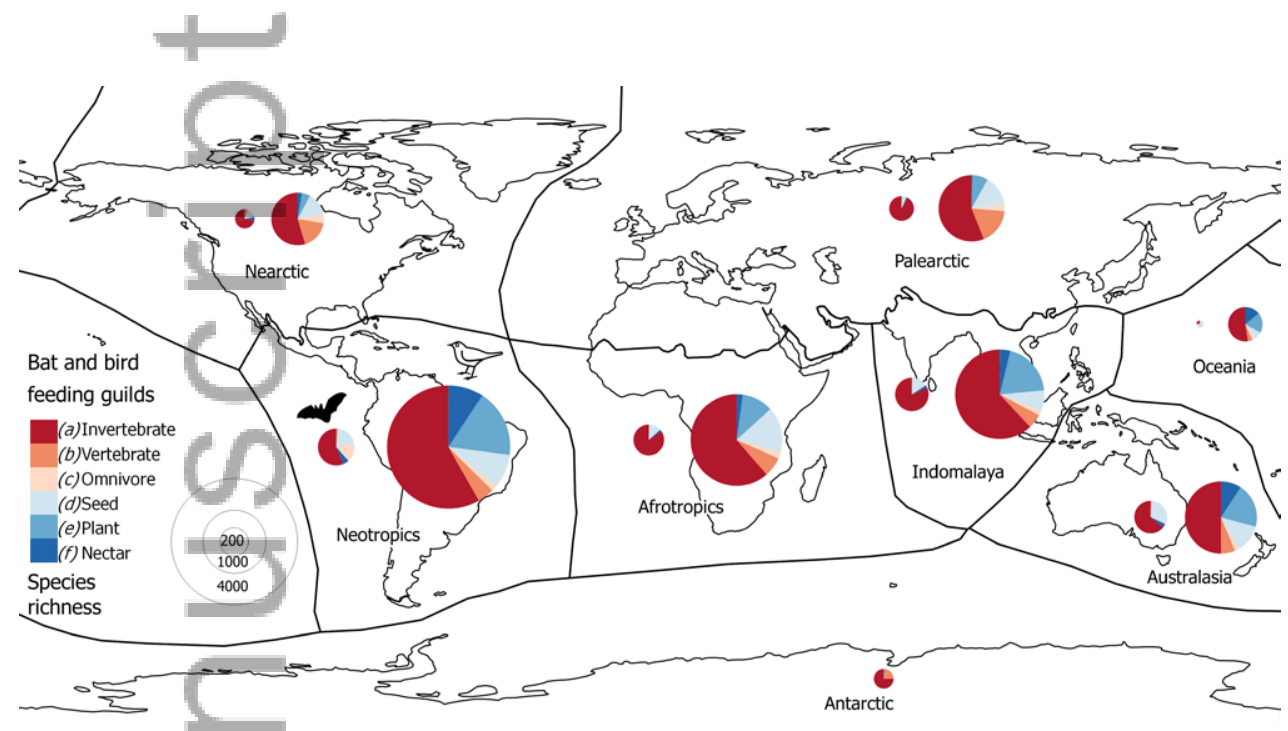

Fig. 1. Bird and bat species' proportions in the six largest feeding guilds (see Section II.3) in different biogeographic realms (following Olson et al., 2001). The size of the pie charts is proportional to bird (right) and bat (left) species richness in each realm.

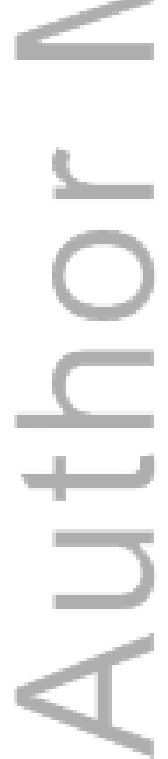




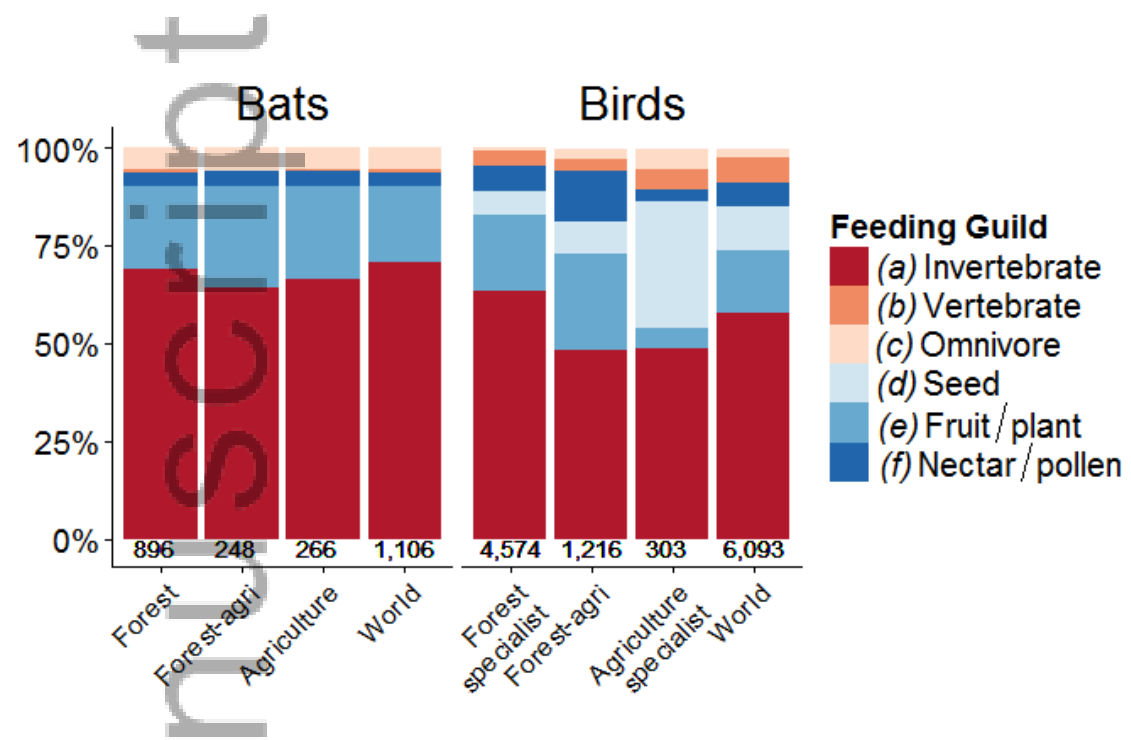

Fig. 2. Feeding-guild composition of bird and bat communities in different habitats. Total number of species in each habitat is indicated below the bars. Forest specialists are birds that occur only in forest or woodland habitats. Agriculture specialists are birds that occur in agricultural areas including agroforests but not natural forest or woodland habitats. Forest-agri birds occur in both agricultural areas and forests/woodland. See Sections II.3 and II.4 for details of the classification of feeding guilds and habitats. The graph for birds is adapted from Sekercioglu (2012), with permission of Springer-Verlag.

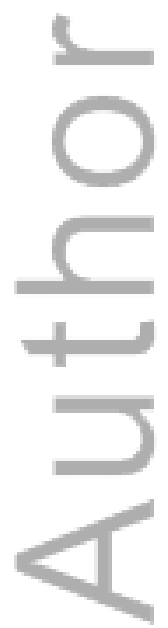




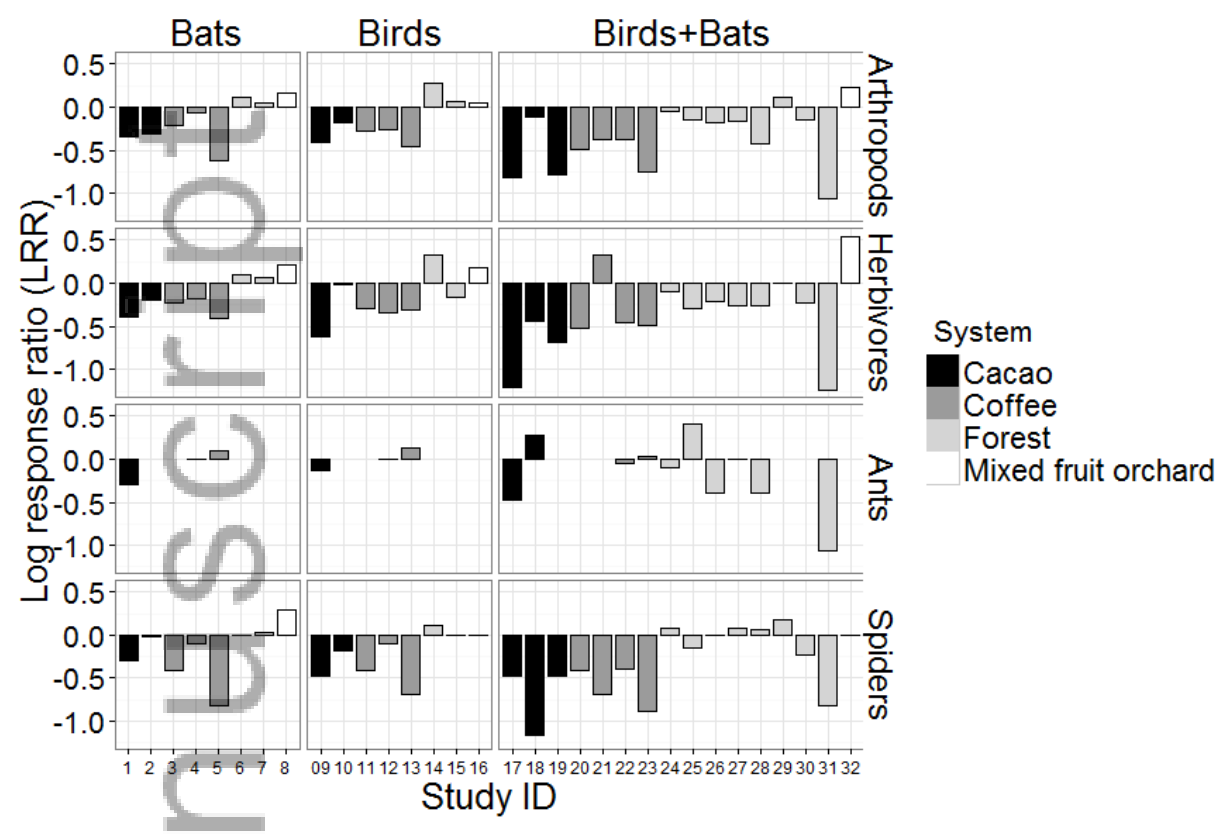

Fig. 3. Effect sizes of bird and bat suppression of arthropod abundance for different groups and studies in cacao and coffee plantations, tropical forests and mixed fruit orchards. Effects on arthropods were calculated using log response ratios $[\mathrm{LRR}=\ln$ (control mean/exclosure mean)]. A more negative LRR indicates a stronger negative effect of predator on prey abundance. Note that ants were not sampled in all studies (no data displayed for respective study ID). Original data, study ID numbers and additional details are given in Table S1.

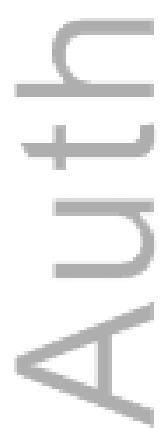




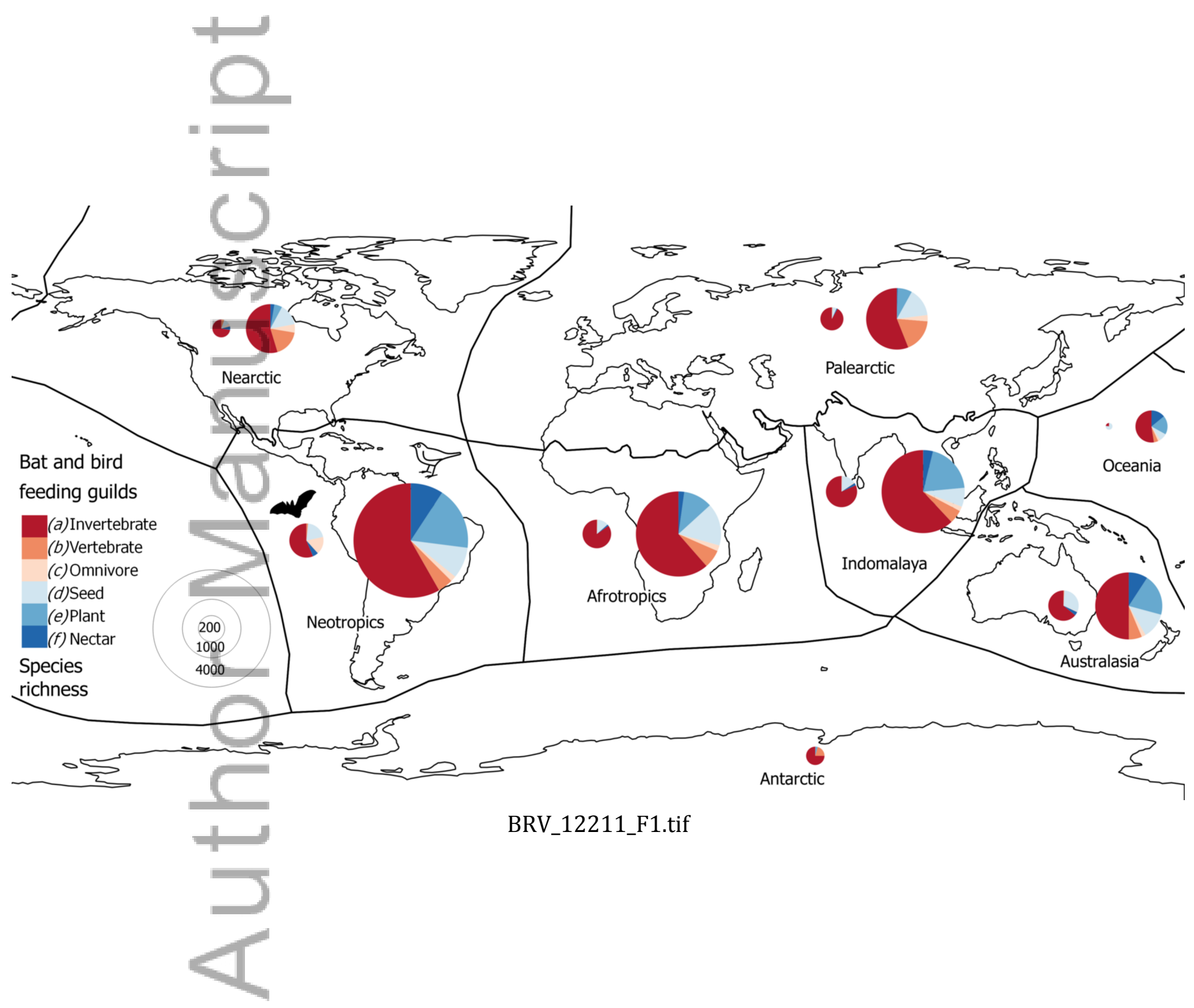

This article is protected by copyright. All rights reserved. 


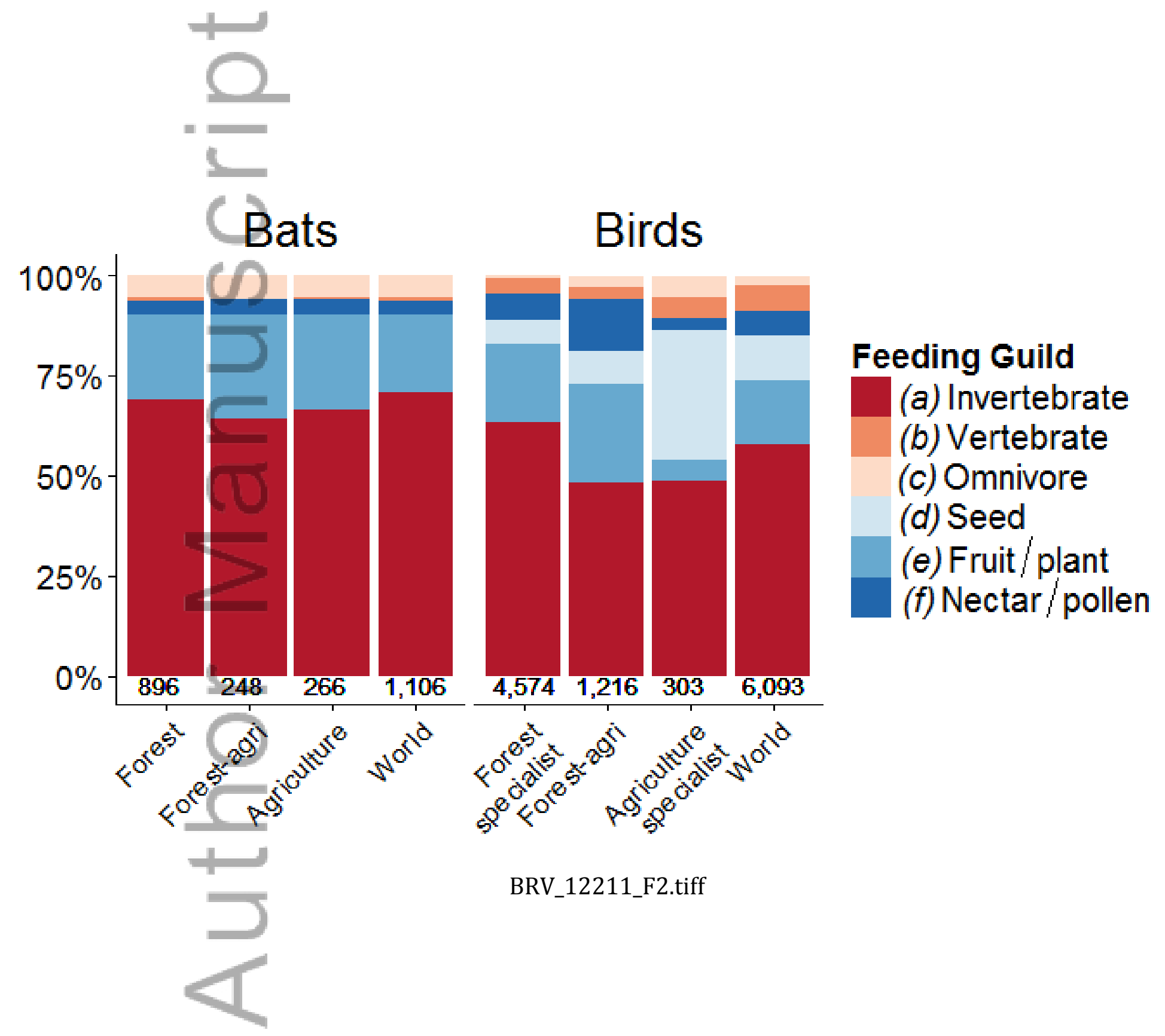




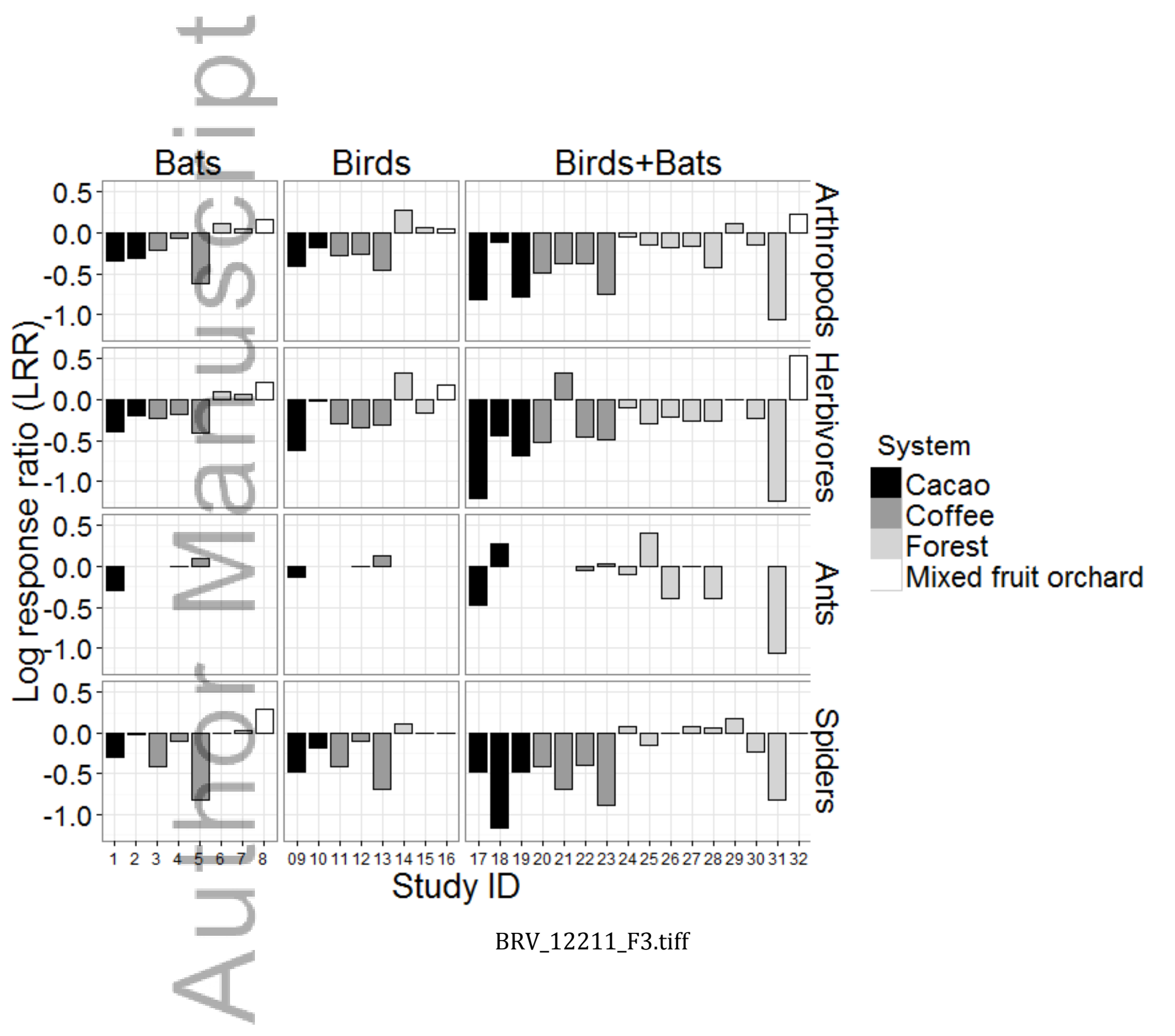

This article is protected by copyright. All rights reserved. 